\title{
SOLITARY PULMONARY HYPERTENSION
}

\author{
BY \\ WILLIAM EVANS, D. S. SHORT,* AND D. EVAN BEDFORD \\ From the London, Middlesex, and National Heart Hospitals \\ Received August 21, 1956
}

An increased resistance to the pulmonary circulation in chronic lung disease has long been known as a cause of right ventricular enlargement, and Graham Steell (1888) described functional pulmonary incompetence due to high pressure in the pulmonary artery in mitral stenosis. The modern conception of pulmonary hypertension was introduced by Moschowitz (1927) who was the first to recognize it in various forms of heart disease, in chronic lung disease, and in pulmonary arterial disease, and to describe its clinical signs. The advent of cardiac catheterization has enabled us to test the clinical signs identified with pulmonary hypertension, to measure its severity, and to discover conditions like congenital cardiac or vascular fistulæ that may be associated with it.

We may define pulmonary hypertension as a persistent elevation of pulmonary arterial pressure sufficient to cause enlargement and ultimately failure of the right ventricle. The diagnosis rests on the clinical, electrocardiographic, and radiological findings.

It is expedient to divide pulmonary hypertension into four distinct clinical groups. In the first group the pulmonary hypertension is associated with chronic lung disease like emphysema, congenital cystic disease, and anthracosis. In the second group it is associated with heart disease like mitral stenosis or certain congenital cardiovascular defects. In a third group, it is caused by obstructive pulmonary arterial lesions such as recurring embolism, bilharzial endarteritis, neoplasm, or periarteritis nodosa. In the fourth group of patients, hypertensive pulmonary vascular disease is an isolated finding.

It is with this last group that our present paper deals and we describe 11 cases of solitary pulmonary hypertension in the sense defined, all of which were examined clinically and at necropsy; this and subsequent histological examination proved the absence of disease of the lung parenchyma and of any heart disease other than right ventricular hypertrophy, so confining the cause of pulmonary hypertension to the lesser pulmonary arteries. The clinical diagnosis of pulmonary hypertension is no longer difficult, and it is from a careful pathological examination that knowledge of the condition will increase. It has been our purpose, therefore, to describe in some detail the pathological findings in our 11 patients and to search in them for an explanation of the pulmonary hypertension which had in turn given rise to enlargement and failure of the right ventricle and ultimately to the demise of the patient.

The Method of Investigation. A routine clinical, electrocardiographic, and radiological examination was made in all 11 patients, and cardiac catheterization was performed in 7 of them. At necropsy the heart was weighed and the degree of right ventricular hypertiophy estimated by measuring the thickness of its wall and complaring itwith that of the left ventricle. Sometimes the free wall of each ventricle was weighed ater separation at the septum.

Special attention was paid to the lung and its vasculature. After opening the pulmonary trunk to exclude the presence of massive embolism, the lungs were removed and one was usually preserved intact for arteriography. The perfusion material used to obtain this pulmonary arteriogram was bismuth oxychloride in gelatine, and the technique devised by Shillingford at the London Hospital 
was followed. Injection of the bronchial arteries in cases outside this series failed to yield additional information of value. The lung, usually inflated to life-size following the injection, was subsequently radiographed in both postero-anterior and lateral projections and also stereoscopically. The radiograph was then magnified, using a fine grain film so that the arterioles were rendered visible as far as vessels of $0.03 \mathrm{~mm}$. in diameter (Short, 1956).

After fixation in formalin, sections of the injected lung were taken for histological examination, and particularly from places where the arteriogram indicated interruption of the circulation. As a rule, five samples were removed for microsc opy from each lung, including at least one block from each lobe. The sections were stained with either Hart or Verhoff elastic stains combined with Van Gieson, as well as with hæmatoxylin and eosin; sometimes serial sections were examined in this way.

\section{AGE AND SEX}

The youngest of our 11 patients was aged 7 and the oldest 64 years at death; of the remainder, four were from 20 to 29 and five from 30 to 39 years. Brenner (1935) stated that primary pulmonary vascular disease occurred mostly in childhood, adolescence, and early adult life, and certainly the majority of authentic cases are under 40 years of age. The disease is now being recognized more often in children and Berthrong and Cochran (1955) have reported the condition in 9 children all examined at necropsy.

All our patients were female. Earlier statistics (Brenner, 1935; Brill and Krygier, 1941) gave the sex incidence as even, but Dresdale et al. (1951) found that 60 per cent of reported cases were female, and in recent papers a female predominance is still more evident.

\section{SYMPTOMS}

Dyspnæa. The first and dominant symptom was dyspnœa. Sometimes this developed unexpectedly during exercise or after some trivial illness; sometimes it came on more gradually. Once appreciable dyspnœa had developed, it usually increased rapidly until eventually even slight effort provoked distressing breathlessness, often accompanied by oppression in the chest and a sense of choking and by faintness or exhaustion. Six of our patients developed orthopnœa, and five had paroxysms of dyspnœa often associated with chest pain, faintness, or even brief syncope. In these attacks the pulse was rapid and very small, and cyanosis became accentuated.

Cardiac Pain. Pain of anginal type and distribution occurred in 6 patients. Sometimes it was provoked by effort and sometimes it occurred at rest or at night, but always it was associated with dyspnœa and this distinguished it from the usual form of coronary pain. One patient, aged 64, who for five years had been subject on exertion to constricting upper chest pain extending into both arms and associated with dyspnœa, had a severe attack, lasting ten minutes and accompanied by syncope, that was diagnosed at the time as coronary thrombosis. Another patient subject to effort pain later developed paroxysms of dyspnœa with constrictive pain lasting ten minutes, sometimes accompanied by vomiting.

Angina pectoris in pulmonary vascular disease was recognized by Posselt (1908) and by Vaquez and Giroux (1908) who named it hypercyanotic pulmonary angina, and this term was also adopted by Arrillaga (1912) in his original account of Ayerza's disease. An identical form of angina occurs in pulmonary hypertension associated with mitral stenosis or with congenital intracardiac shunts. In these conditions also, it is associated with dyspnœa, and when provoked by effort it tends to subside slowly with rest.

Viar and Harrison (1952) discussed this form of cardiac pain and suggested that it arose from distension of the pulmonary artery. Stuckey (1955) specially investigated its pathogenesis and concluded that it was essentially related to a severely restricted cardiac output and a high pulmonary vascular resistance, with an inadequate coronary flow on effort. The exercise electrocardiogram showed ischæmic changes and we have confirmed this. Cyanosis, if present, may be intensified, but the hall-mark of pulmonary angina is dyspnœa rather than cyanosis. 
Syncope. Five of our patients had syncopal attacks, sometimes provoked by effort, sometimes associated with paroxysms of dyspnœa or pain, and sometimes repetitive. Howarth and Lowe (1953) found that, in primary pulmonary hypertension, the pulmonary arterial pressure rose steeply with effort, after which the right ventricular output fell and its diastolic pressure rose, so that they postulated an acute right ventricular failure as the cause of syncope. Both pain and syncope may occur in the same patient, and there can be no doubt that both are symptoms of a restricted cardiac output. Exhaustion and weakness on effort are lesser symptoms from the same cause.

\section{Physical Signs}

Those patients seen at the start of their illness showed little or no cyanosis at rest, though it was sometimes present during exertion. Later, cyanosis sometimes became conspicuous especially during paroxysms of dyspnœa. Arterial anoxæmia was rarely sufficient by itself to account for cyanosis so that a low cardiac output and polycythæmia were mostly responsible for it. Clubbing of the fingers was absent in all but one, where it was slight.

The pulse was usually small or became so later and was sometimes impalpable. Auricular fibrillation was never observed. The blood pressure was usually normal or low when first recorded, and invariably low in the later stages: in two patients, the initial blood pressure was slightly raised. In six cases, the jugular venous pulse exhibited a prominent or even occasionally a giant auricular wave; with the onset of congestive failure, this wave became less obvious and was often overshadowed by the systolic wave of tricuspid incompetence.

Palpation almost always provided evidence of right ventricular hypertrophy. The apex beat, sometimes displaced to the left, was of right ventricular type. A systolic lift over the conus arteriosus was usual, and occasionally there was a widespread systolic impulse from sternum to apex, but in general this pulsation was less widespread and less forcible than that observed in cases of atrial septal defect. A diastolic shock synchronous with pulmonary valvular closure was often present.

A constant finding on auscultation was a loud pulmonary second sound, present in all cases but one, where it was obscured by a loud diastolic murmur. Generally, the second sound at the pulmonary area was obviously but closely split, the second or pulmonary element being the louder. A pulmonary early systolic click or ejection sound (Lian, 1940; Leatham and Vogelpoel, 1954) was heard in six cases, sometimes followed by a systolic murmur which was never loud. A blowing diastolic murmur of pulmonary incompetence was present at some stage in four cases. An apical systolic murmur was heard in several, which may have been of tricuspid rather than mitral origin. A triple rhythm at the apex or over the right ventricle was noticed in 6 cases; usually it was due to a third heart sound, but occasionally to an auricular sound. Once (Case 1) a sound that resembled a mitral opening snap was heard in early diastole.

\section{SPECIAL INVESTIGATIONS}

Blood Examination. Slight polycythæmia was present in 8 of the 9 where a blood count was recorded, the highest red cell count being 8.8 million and the highest hæmoglobin 140 per cent. A polymorphonuclear leucocytosis occurred in four, the highest white cell count being 18,900 per c.mm. The Wassermann reaction was always negative. The arterial oxygen saturation, recorded in six cases, varied from 63 to 93 per cent, being usually between 84 and 93 per cent. The cause of this arterial anoxæmia has not been adequately explained: it was not due to a patent foramen ovale, for this was only present in two cases, and in one of them the aperture merely admitted a probe; it may have been caused by a shunt through the enlarged broncho-pulmonary anastomoses.

Radiological Examination. In the anterior view, the right atrium was enlarged in 9 cases, and enlargement towards the left, interpreted as due to the right ventricle, occurred in 10 cases. Right ventricular enlargement involving the conus gave a blunted or square shape to the left heart contour compared with the more pointed oval of left ventricular enlargement. The pulmonary trunk was dilated in every case; it was aneurysmal in 3, much enlarged in 4 , and merely prominent in 4 cases. The aorta, in the anterior view, appeared relatively small in 9 and normal in 2 cases. 
The main pulmonary branches were enlarged in 9 and normal in 2 cases. The peripheral lung fields were oligæmic in 8 , and never plethoric. The large hilar vascular shadows often faded abruptly so that the distal arterial branches appeared unduly narrow (Fig. 1 to 4). One case showed the scar of a pulmonary infarct but no others showed any evidence of disease of the lung parenchyma.

Electrocardiogram. The electrocardiogram always presented unequivocal evidence of right ventricular hypertrophy. The standard leads always showed right axis deviation combined with $T$ wave inversion in leads III and II in 7 cases. Lead V1 or CR1 always showed a dominant $R$ wave and a negative $T$ wave except once when it was flat. Large and usually sharply pointed $P$ waves in leads II, or II and III, were seen in 9 cases, and usually the P waves were also large in the right chest leads. There was always normal sinus rhythm (Fig. 5 and 6).

The phonocardiogram, when recorded, confirmed the auscultatory findings (Fig. 7). Splitting of the second sound was narrow as a rule, with accentuation of the pulmonary component. When a pulmonary systolic murmur was recorded its bulk was in mid-systole and it ended before reaching the pulmonary second sound. The start of the murmur was sometimes signalled by the early systolic ejection sound. Once the phonocardiogram showed a high frequency sound in early diastole (Fig. 7D).

Cardiac Catheterization. Solitary pulmonary hypertension cannot be diagnosed with certainty unless the presence of a congenital intra-cardiac fistula has been excluded. For this purpose direct exploration of the cardiac septa and of the ductus arteriosus by catheter is necessary, and even this is not always conclusive; blood-gas analysis cannot exclude a balanced shunt. For this reason we have omitted from our present series a number of cases in which the diagnosis of solitary pulmonary hypertension was supported by catheterization, and have restricted it to those cases proved by necropsy.

The pulmonary artery pressure was recorded in 6 cases of this series and it was always considerably raised, being $118 / 80,70 / 40$, and $67 / 25 \mathrm{~mm}$. in 3 cases, and in the other 3 the mean pressure was 107,74 , and $63 \mathrm{~mm}$. respectively. In another case the right ventricular mean pressure was $47 \mathrm{~mm}$. The pulmonary capillary pressure was never raised and the cardiac output when measured was low.

\section{Clinical Course}

Sometimes the onset of dyspnœa was quite abrupt. Thus, in one patient it started with a breathless attack while alighting from a bus, in another it followed an attack of bronchitis, and two patients, accustomed to vigorous exercise, found themselves unexpectedly incapacitated at tennis and hockey. Tightness in the chest, cyanosis, fatigue, faintness or syncope were soon linked to dyspnœa on exertion.

Once overt dyspnœa had occurred, it progressed rapidly, activity became much restricted and, when cyanosis at rest was evident, effort of any sort provoked extraordinary distress. Orthopnœa, paroxysms of dyspnœa with intense cyanosis, chest pain, and occasionally repeated syncope with a small or impalpable pulse characterized the final stages of the disease.

In 10 cases in which the date of onset of symptoms could be determined, the subsequent span of life varied from five months to seven years, the average being approximately $2 \frac{1}{2}$ years. The shortest survival was in the youngest patient, aged 7, and the longest in the oldest patient, aged 64 . Case 9 was exceptional in that a cardiac murmur had been noticed in childhood, syncopal attacks on effort began at the age of 16 , severe dyspnœa with chest pain at the age of 26 , and she died during pregnancy, aged 27. Necropsy showed congenital aneurysmal dilatation of the pulmonary artery in addition to pulmonary vascular disease.

Two patients died during pregnancy which had greatly aggravated their symptoms. Congestive heart failure appeared before death in 10 patients though in 5 of them death was sudden from syncope or peripheral circulatory failure. In three, a terminal state of drowsiness and apathy set in, and one patient died following an epileptic fit. 


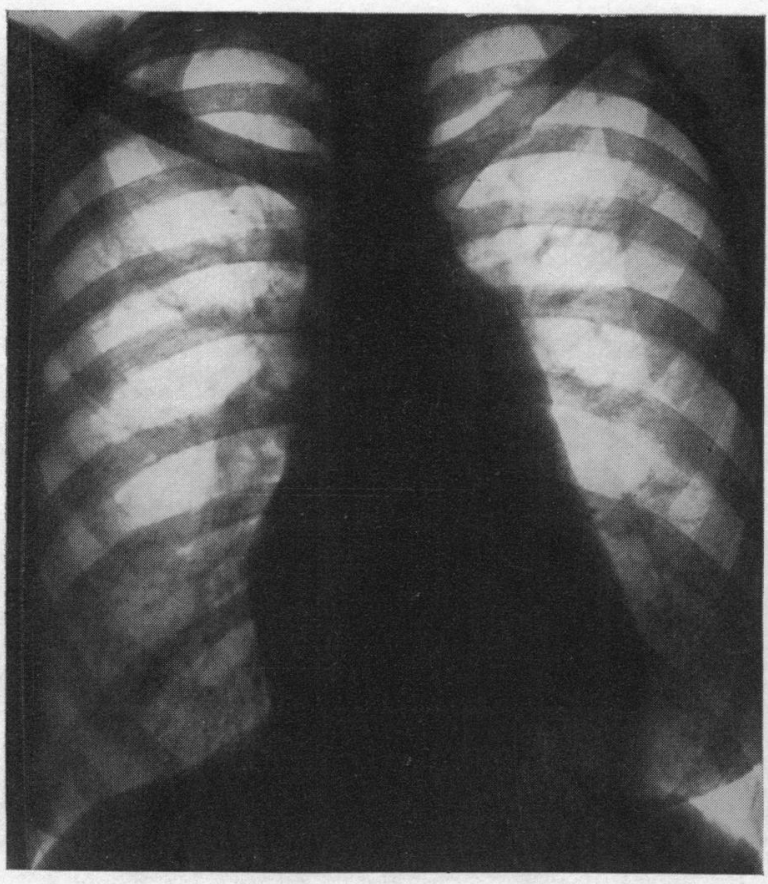

Fig. 1.-Moderate enlargement of the pulmonary artery and prominence of its main branches. Ischæmia of peripheral lung fields. Case 5.

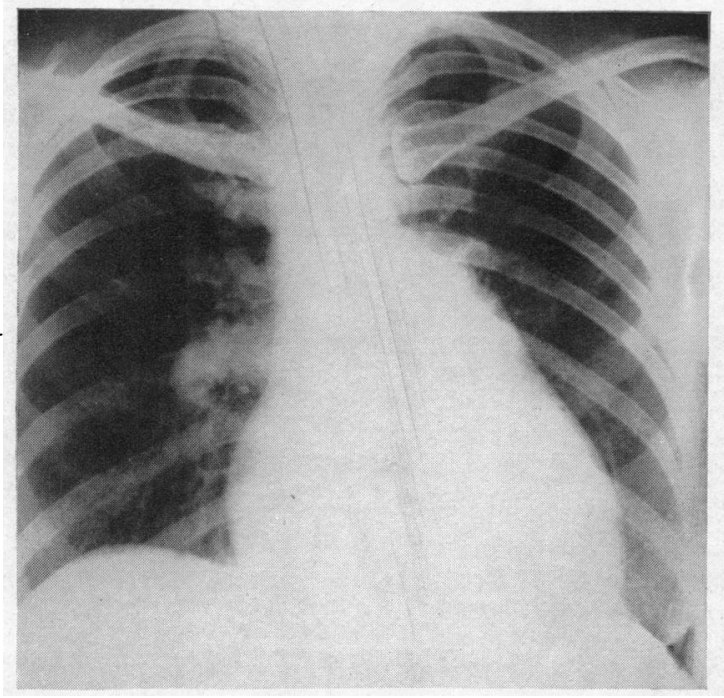

Fig. 3.-Considerable enlargement of the heart and of the pulmonary artery with prominence of the right main branch; ischæmia of peripheral lung fields. Case 6.

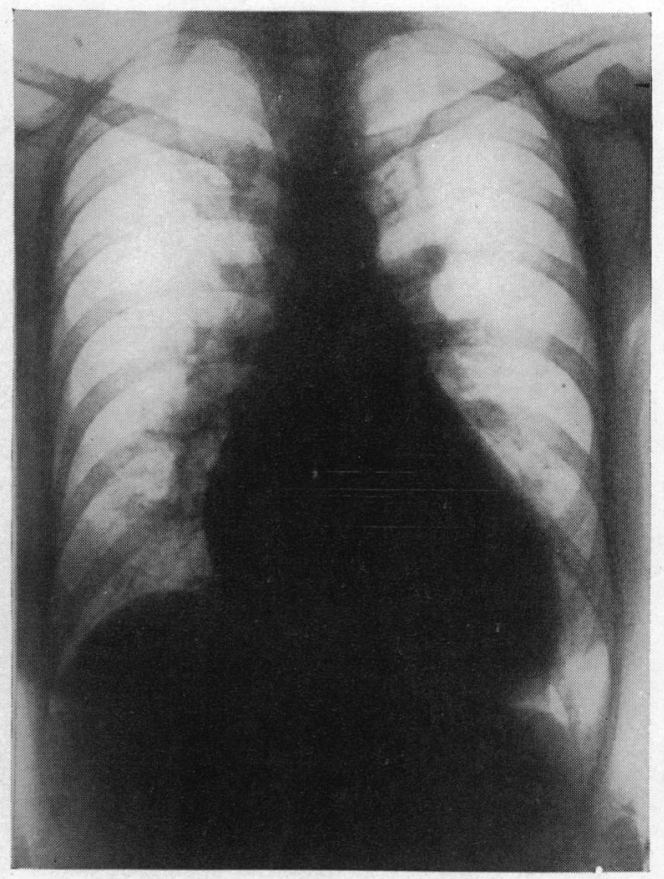

FIG. 2.-Moderate enlargement of the heart. Slight enlargement of the pulmonary artery and prominence of the main branches, but clear peripheral lung fields. Case 3.

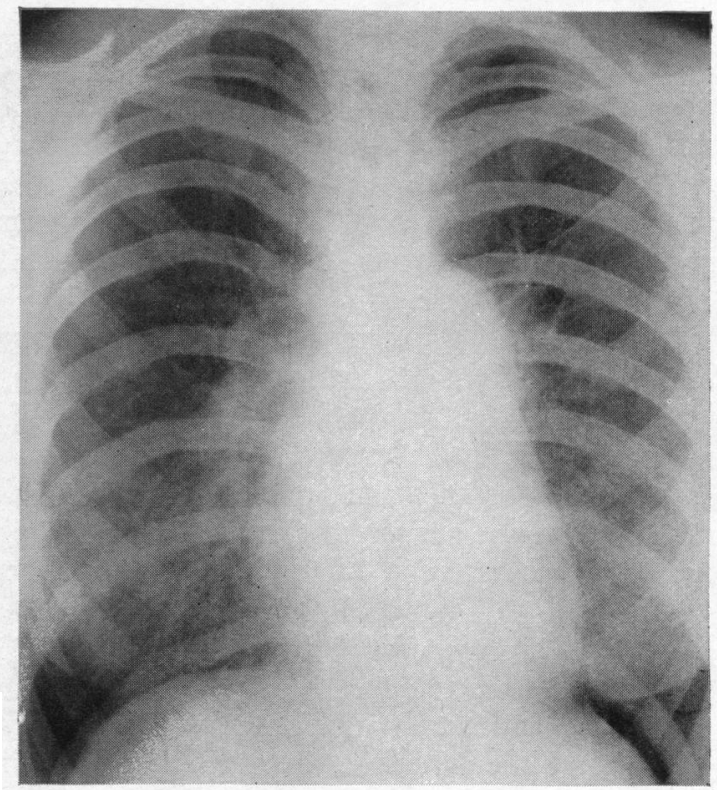

Fig. 4.-Slight enlargement of right atrium. Small aorta. Great prominence of pulmonary artery and less of its main branches. Secondary pulmonary branches visible, but ischæmia of peripheral lung fields. Case 4. 


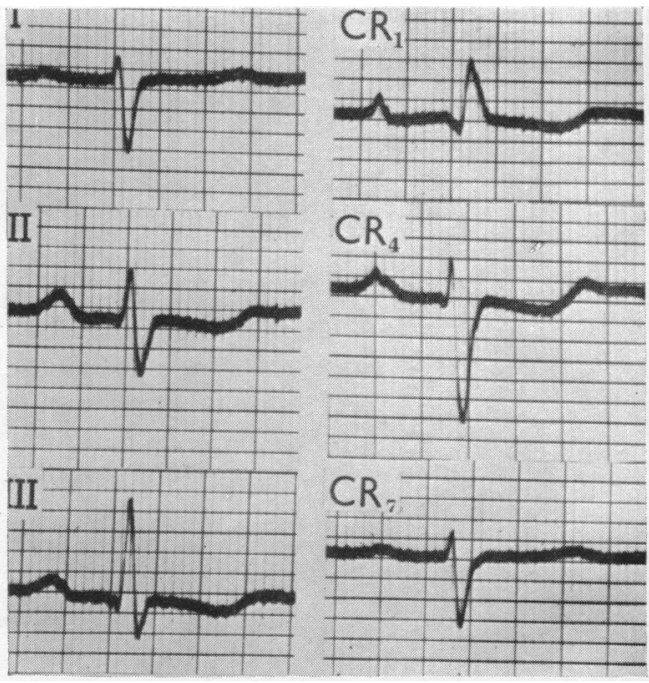

FIG. 5.-Right ventricular preponderance. Case 1.

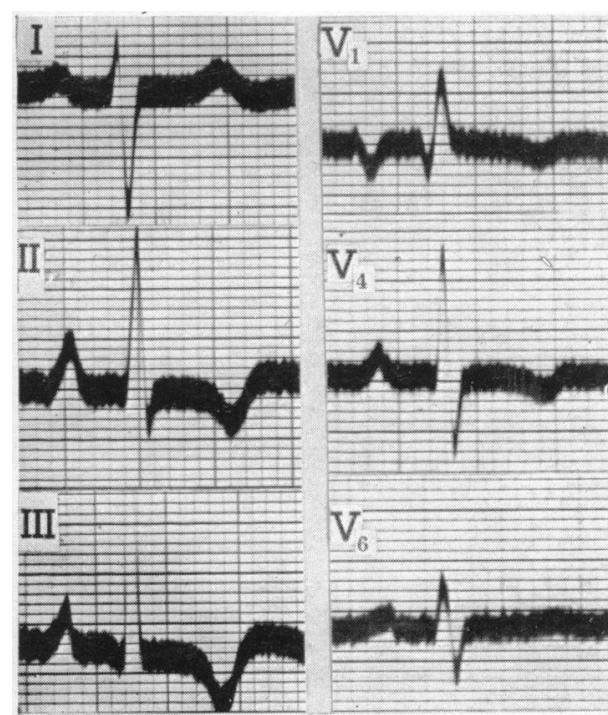

FIG. 6.-Right atrial and ventricular preponderance. Case 3.

\section{DIAGNOSIS}

The diagnosis of solitary pulmonary hypertension can only be made after all other varieties have been excluded. Usually it is not difficult to recognize chronic lung disease by its long and characteristic history and by its clinical and radiological signs. It causes manifest central cyanosis, often finger clubbing, and there may be an increased cardiac output with a full pulse and warm extremities.

Mitral stenosis is the commonest condition to be found in association with severe pulmonary hypertension and this may cause the customary murmurs to wane and even to disappear, although the opening snap persists as a rule. Rarely, the recognition of a snap sound in early diastole presents a difficulty as happened in our Case 1, when phonocardiography helped to decide. There is usually a long history of heart disease, and left atrial enlargement on radioscopy; an inconstant diastolic murmur may be detected by repeated auscultation. Apart from these differential features, severe pulmonary hypertension associated with mitral stenosis presents the same low cardiac output syndrome of anginal pain, faintness or syncope, peripheral cyanosis and small pulse, as occurs in the solitary form.

Difficulty in diagnosis may also arise when pulmonary hypertension is associated with congenital defects such as patent ductus arteriosus and intracardiac shunts, for the characteristic murmurs may disappear as the pressures in the two sides of the heart equalize and the shunt becomes balanced or even reversed. In expert hands the cardiac catheter can usually be passed through a widely patent ductus or an atrial septal defect, but clinical differentiation may be difficult, and Whitaker et al. (1955) have suggested that many cases diagnosed as idiopathic pulmonary hypertension are, in fact, cases of patent ductus. In most such cases, however, there is a history of heart disease recognized in childhood, finger clubbing is more common, and if the shunt is reversed, angiocardiography can show premature filling of the descending aorta from the pulmonary artery. Pulmonary hypertension associated with atrial septal defect cannot always be distinguished from the solitary type by clinical examination, but there is usually a longer history of heart disease or of cardiac symptoms, while cardiac catheterization should be diagnostic. Dexter (1956) regards cases of pulmonary hypertension with a small atrial septal defect as examples of primary pulmonary vascular disease.

Pulmonary hypertension and right heart failure due to repeated pulmonary embolism may be difficult or impossible to distinguish on clinical grounds from solitary pulmonary hypertension, and 


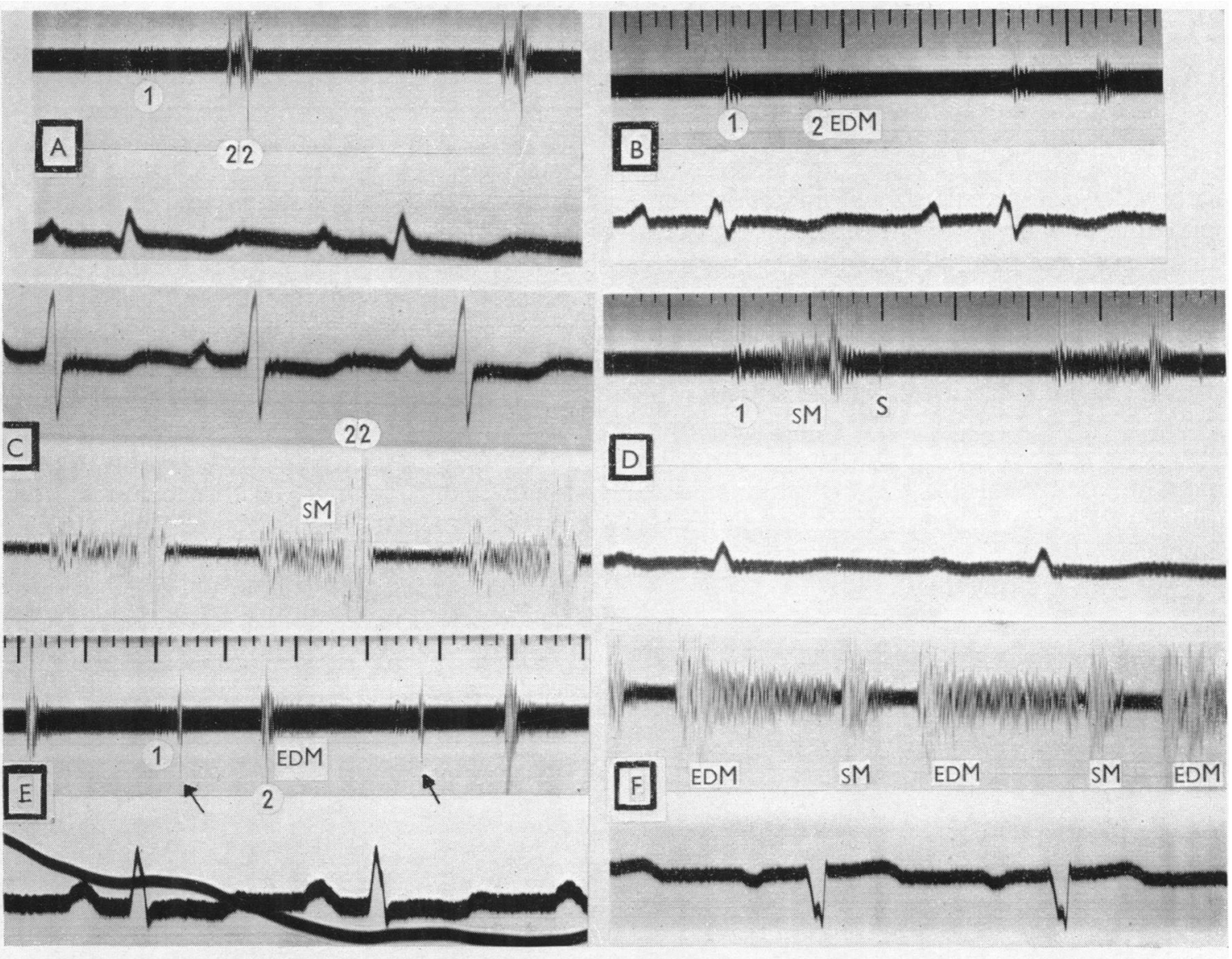

Fig. 7.-Representative phonocardiograms from our series. (A) Close splitting of second heart sound with accentuation of its pulmonary component. (B) Early diastolic murmur of pulmonary incompetence. (C) Systolic murmur ending at aortic component of closely split second sound whose pulmonary element is accentuated. (D) Sound in early diastole from Case 1. (E) Sound in early systole and an early diastolic murmur of pulmonary incompetence. (F) Long diastolic murmur of pulmonary incompetence and mid-systolic murmur which stops short of the second sound. The reference electrocardiogram is lead II in E and F, elsewhere CR1.

even at necropsy the distinction can be difficult, particularly when the small arteries are involved. In all forms of severe pulmonary hypertension with reduced cardiac output, thrombotic or even embolic occlusion of the larger pulmonary arteries is quite common, and only careful examination of the whole pulmonary vasculature can decide the primary lesion. As illustrative of this difficulty, we may mention two patients reported by Goedel (1930) in whom right heart enlargement and failure were associated with thrombotic lesions in the large pulmonary arteries and with intimal hyperplasia in the small arteries. Brenner (1935) included both of Goedel's cases in his group of primary pulmonary vascular sclerosis, and Brill and Krygier (1941) regarded them likewise, but Lenègre and Gerbaux (1952 and 1955), on the other hand, claimed them as examples of heart disease due to pulmonary arterial thrombosis. We also met this difficulty in three cases that, though regarded as having solitary pulmonary hypertension during life, were found at necropsy to have massive pulmonary embolism or thrombosis and systemic venous thrombosis.

In general, embolic or thrombotic pulmonary hypertension occurs at a later age than the solitary form, usually after 40 , and episodes of pulmonary infarction, pleural effusion, or peripheral venous thrombosis can sometimes be recognized at the onset or from the history. In the later stages, when the thrombus has organized, the symptoms and signs may be indistinguishable from those 
of solitary pulmonary hypertension. Sometimes radioscopy shows immobility of the thrombosed hilar branches, or an abrupt amputation of a main branch beyond the seat of thrombosis.

\section{Pathology}

The liver, spleen, kidneys, and other systemic organs were usually the seat of chronic venous congestion and occasionally of infarction, but the most important changes were found in the heart and lungs. Cardiac malformations like atrial or ventricular septal defects and patent ductus arteriosus were naturally excluded in every case; there was valvular patency of the foramen ovale twice, one case admitting a probe and the other a pencil. The valves were always healthy; the coronary arteries were free from significant atherosclerosis, and there was no myocardial infarction.

The heart was heavier than normal except in one instance (Case 5). Sometimes the increase was slight, but occasionally the weight was three times the normal. In our 11 women patients it ranged between 250 and $525 \mathrm{~g}$., with an average of $393 \mathrm{~g}$. compared with the normal of about $250 \mathrm{~g}$. Right ventricular hypertrophy, usually with moderate or greater dilatation, was invariably present, and the thickness of the ventricle varied from 7 to $20 \mathrm{~mm}$. compared with 9 to $15 \mathrm{~mm}$. for the left ventricle. Intracardiac thrombosis was present in two cases, involving the right auricle in one and the right auricle and ventricle in the other.

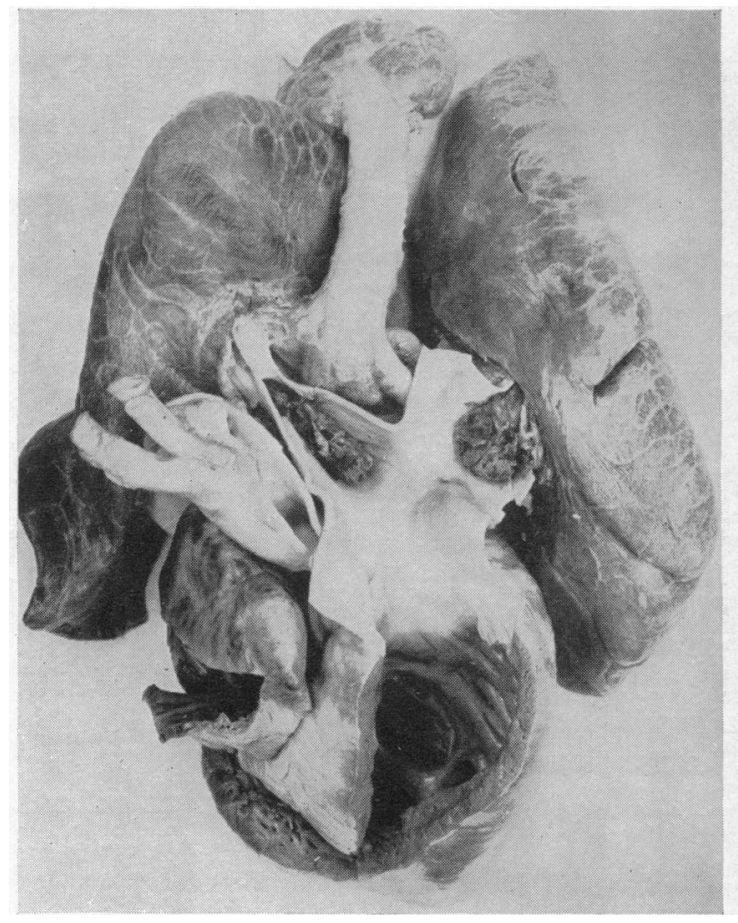

FIG. 8.-Pulmonary thrombosis or embolism complicating pulmonary hypertension in Case 7, aged 7 years. A thrombus is seen filling both main pulmonary arteries.

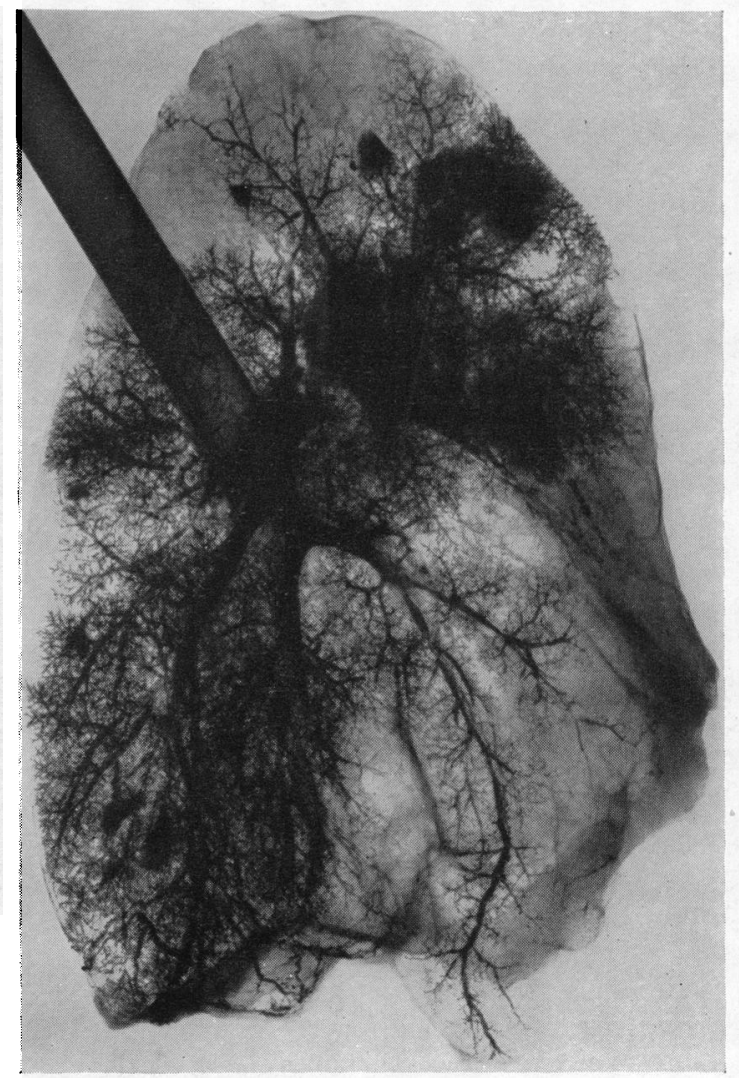

FIG. 9.-Pulmonary arteriogram from Case 1, showing absence of injected material from large areas caused by thrombotic occlusion of some of the segmental arteries. The dense blotches indicate areas of actual infarction. 
The lung parenchyma usually appeared healthy on naked-eye examination apart from areas of infarction in two cases. The pulmonary arterial trunk was always dilated and so as a rule were its main branches in which intimal thickening was more widespread than usual in subjects of the same age. In two cases the trunk or a main branch was thrombosed (Fig. 8). The segmental arteries of 2 to $5 \mathrm{~mm}$. diameter often stood out prominently from the cut surface of the lung. The bronchial arteries in their course to the lungs were never enlarged.

The pulmonary arteriogram clearly portrayed narrowing or occlusion wherever it occurred in the arterial tree. When the larger arteries were occluded by thrombus, the territory they supplied was devoid of opaque material leaving bare areas. In places of actual infarction, the injected medium collected to form irregular blotches which had a granular appearance in the full-sized film (Fig. 9). When the muscular arteries were occluded, they ended blindly, giving to the arteriogram a pruned appearance which has been likened to the denuded shrub in autumn replacing the leafy bush in spring (Evans, 1951) which is its normal appearance (Fig. 10 and 11).

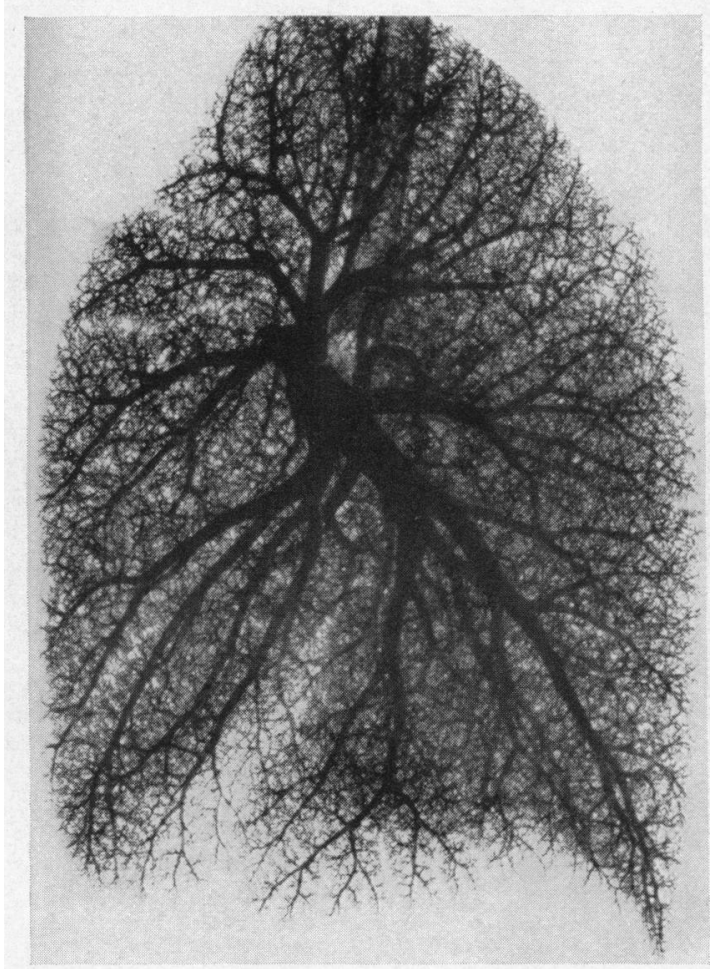

Fig. 10.-Normal pulmonary arteriogram.

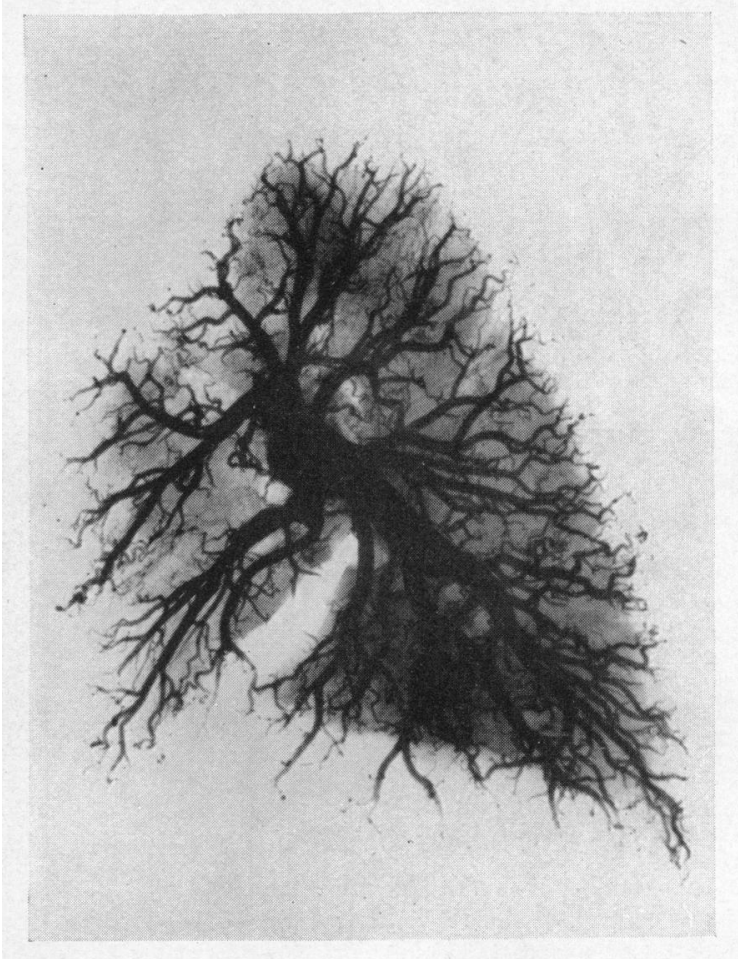

FIG. 11.-Pulmonary arteriogram from Case 4, showing pruning of the lobular vessels following occlusion of many muscular arteries.

When the arterioles were occluded there was obvious impoverishment of the fine tracery at the periphery of the magnified arteriogram (Fig. 12). In some of the cases in which the larger arteries were occluded, anastomotic vessels were seen traversing the pleura, and although a few of these were broncho-pulmonary communications, the majority appeared to be collateral interpulmonary channels which linked the blood supply of adjacent lobules (Fig. 13). The presence of bronchopulmonary communications could be inferred when during injection the opaque mass flowed out of the bronchial artery into the pulmonary artery, and the communications could occasionally be demonstrated in the magnified arteriograms. The pulmonary arteriogram, therefore, has proved 


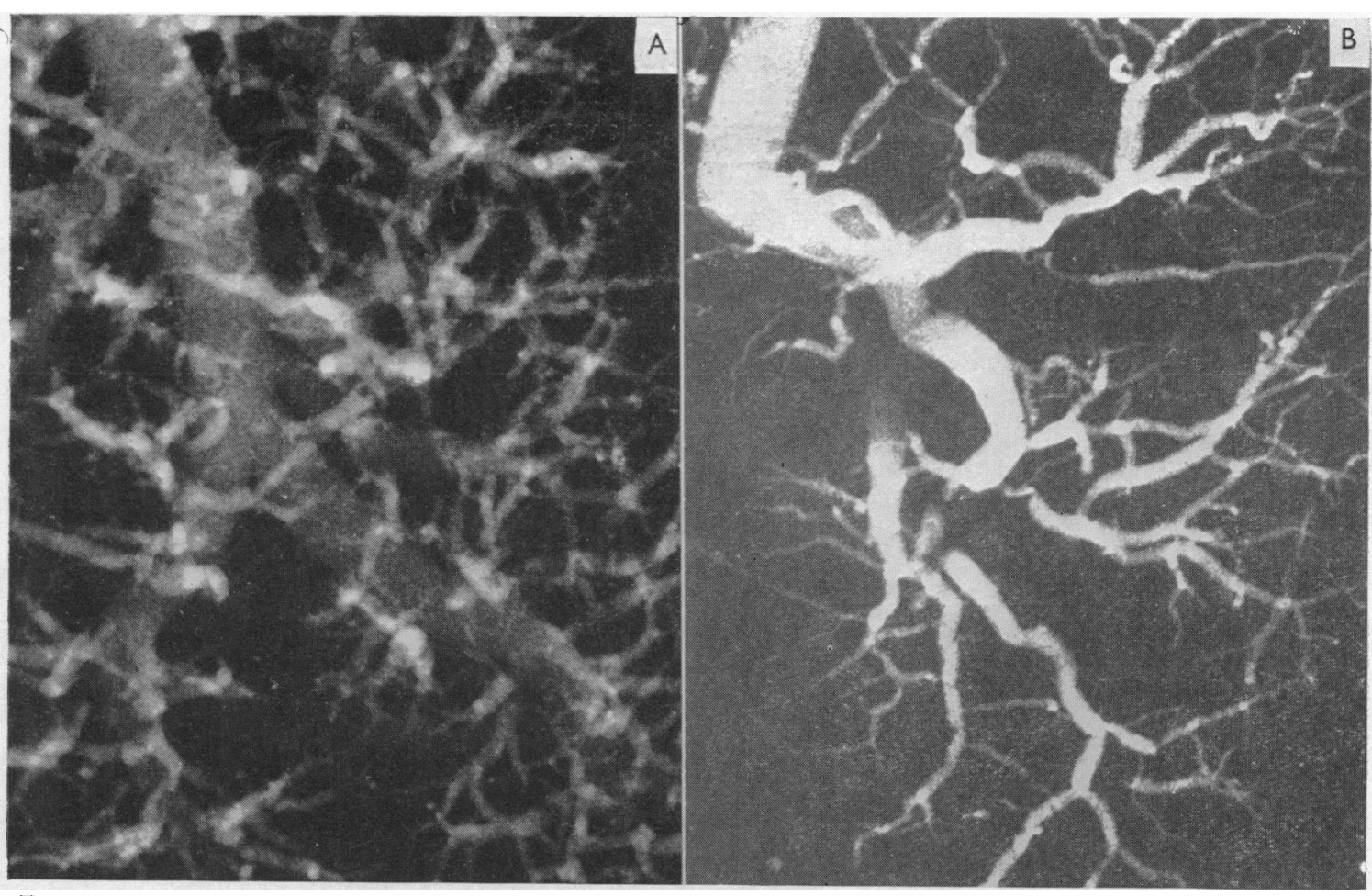

Fig. 12.-Magnified pulmonary arteriogram. (A) is from a normal lung. (B) is from Case 11, showing pruning of the terminal vessels due to narrowing.

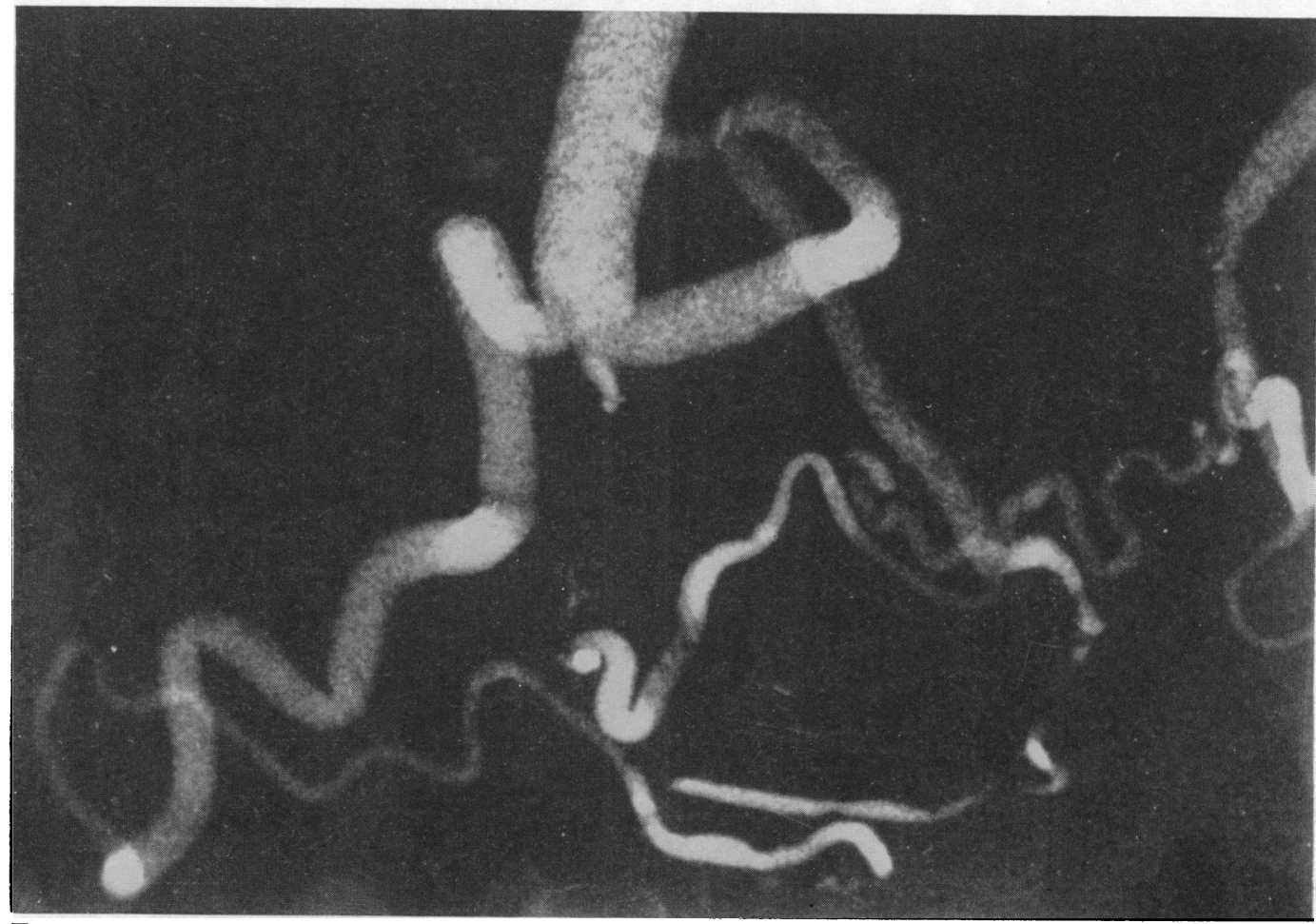

FIG. 13.-Magnified pulmonary arteriogram from Case 4. A muscular artery has been obstructed and proximal to this are a number of collateral interpulmonary channels. 
itself an indispensable test in the pathological investigation of our cases. Thus, it told the extent and site of thrombosis within the larger vessels, delineating pulmonary infarcts especially when stereoscopic films were used, establishing the presence of obstruction within the muscular arteries, and even within the arterioles, indicating the place where sections should be taken for histological study, discovering the presence of abnormal arterial anastomoses, and distinguishing the arterioles from venules at subsequent microscopy.

By histological examination three kinds of pulmonary arteries were recognized and, following the classification given by Brenner (1935), they are designated elastic arteries, muscular arteries, and arterioles. The elastic arteries show three or more well-defined elastic coats (Fig. 14A), the muscular arteries two elastic coats separated by circular muscular fibres (Fig. 14B), and the arterioles a single elastic coat (Fig. 14C). The transition between an elastic and muscular artery takes place where the external diameter of the vessel is approximately $1.0 \mathrm{~mm}$., and between a muscular artery and arteriole where the diameter is about $0.1 \mathrm{~mm}$. The adventitia is not included in a measure of the diameter since it is often ill-defined. It follows that vessels referred to in this paper as muscular arteries correspond with the artérioles musculaires of French authors,

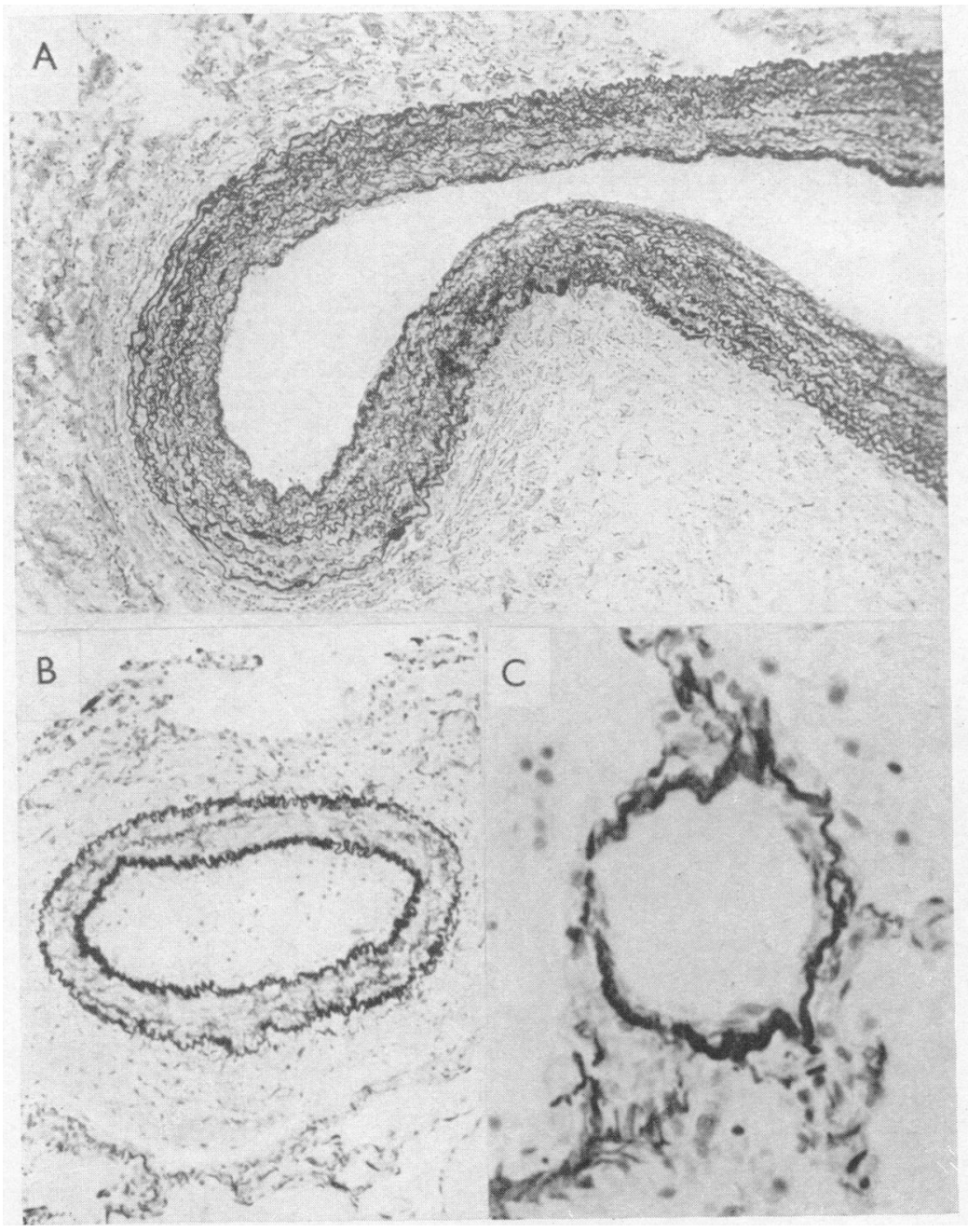

Fig. 14.-Normal pulmonary arteries. (A) Elastic artery $(\times 50)$. (B) Muscular artery $(\times 100)$. (C) Arteriole $(\times 300)$. 
and arterioles to their pré-capillaires. Arterioles closely resemble venules on histological examination and unless they are seen arising from a muscular artery they can only be distinguished with certainty following a pulmonary arteriogram.

Arteriography could not always distinguish the bronchial arteries from branches of the pulmonary artery as both were sometimes filled with the injected material. The histology of the bronchial arteries, however, has been carefully described by Verloop (1948), and the identification of these vessels does not as a rule present any difficulty. Thus, before penetrating the bronchial wall they have a thin muscular coat lined by a dense internal elastic membrane. In the wall of the smaller air passages the longitudinal muscle fibres of the intima of the bronchial arteries increase greatly in number so that the intima is several times thicker than the media, causing the lumen to become very narrow or even closed. In the small bronchial arteries the media may also enlarge, and at the same time its muscle fibres may change in direction and course round the lumen in spiral fashion, ultimately lying almost parallel with the longitudinal fibres of the intima (Fig. 15).

We have elected to describe the histology of lone or solitary pulmonary hypertension by reference to our own material, since in reported cases the location of the vascular changes in the pulmonary arterial tree has not always been exactly defined.

In the elastic arteries intimal thickening was more noticeable than in normal subjects of the same age. Thrombosis of one or two segmental arteries was a common finding, and it sometimes involved the muscular

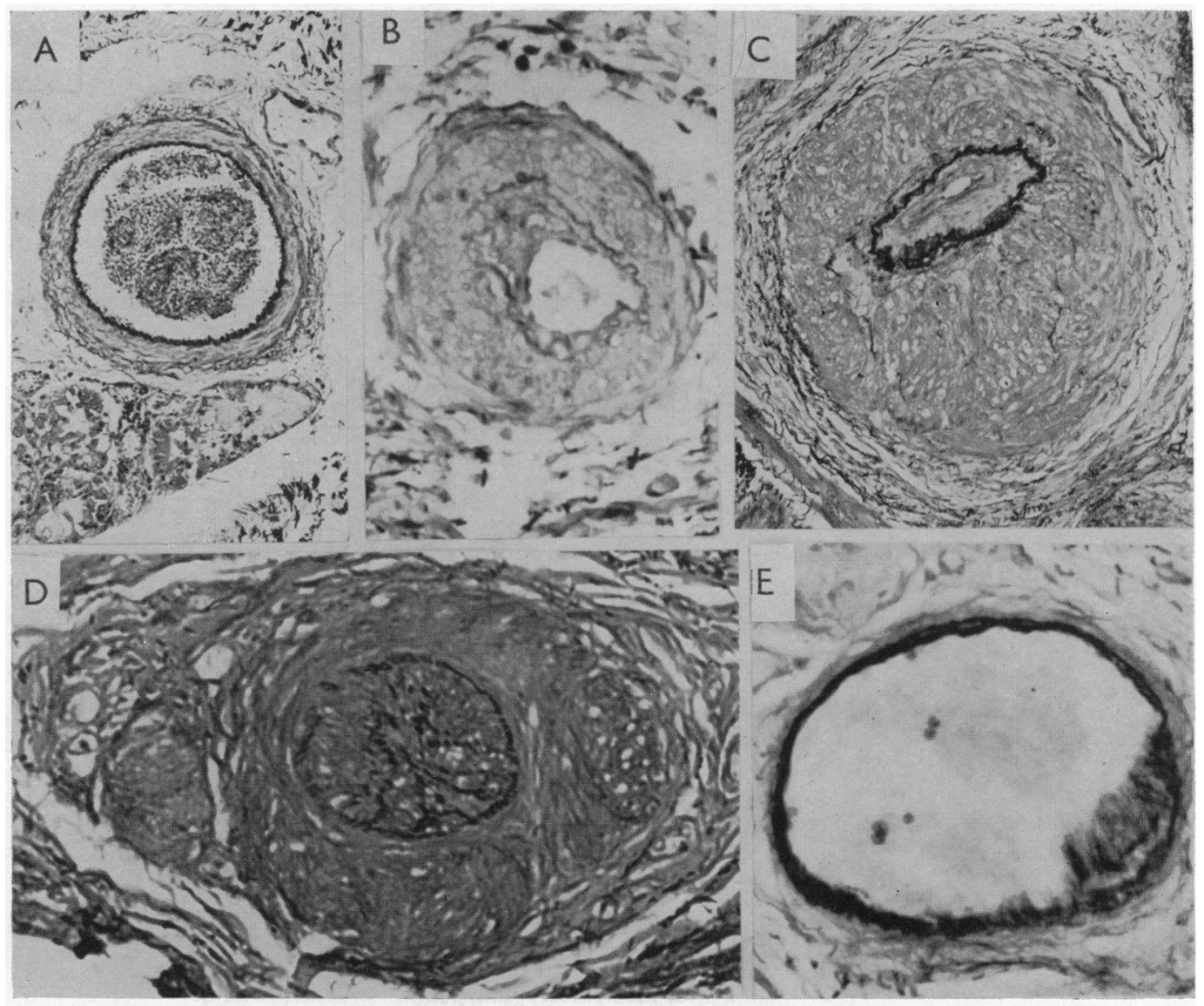

FIG. 15.-Normal bronchial arteries. (A) Free artery with thin muscular coat and dense internal elastic covering $(\times 100)$. (B) and $(C)$ Thin media and great thickening of intima causing great narrowing of the lumen $(\times 300$ and $\times 100$ respectively). (D) Great thickening of media where its muscle fibres course in compartmental bundles. The intima is also thickened obliterating the lumen $(\times 200)$. (E) Thin media with dense elastic lining and large lumen $(\times 300)$. 
arteries. It needs emphasizing that thrombosis is a common complication of pulmonary vascular disease whether of the solitary type or associated with mitral stenosis or congenital heart disease such as atrial septal defect. The finding of thrombosis in the larger arteries does not imply that the vascular disease is primarily embolic or thrombotic, if typical histological changes are found in the small vessels and if the arteriogram shows widespread narrowing of the peripheral pulmonary vasculature.

The most significant changes in our cases had taken place in the muscular arteries and arterioles. These vessels were often partially or wholly occluded by an abnormal sparsely cellular tissue, and it has been impossible to decide with certainty from histological examination whether the tissue was of thrombotic origin or the result of an intimal reaction. Harrison (1948) showed that pulmonary emboli produced experimentally in the animal may in the course of time shrink to mere plaques of intimal thickening. In the case of solitary pulmonary hypertension, however, we believe that the process is mostly reactive or reparative, even though in part thrombotic, and we have therefore styled it intimal proliferation.

In the muscular arteries this intimal change was related to areas of medial hypoplasia or aplasia, or very rarely focal necrosis. Medial hypoplasia did not as a rule disturb the external circular appearance of the artery because the outer elastic coat of the media, supported by the adventitia, usually remained unindented. On the other hand, the inner elastic coat approached the external coat where the media showed hypoplasia, becoming contiguous with it at sites of medial aplasia (Fig. 16 to 19). Where intimal prolifera-

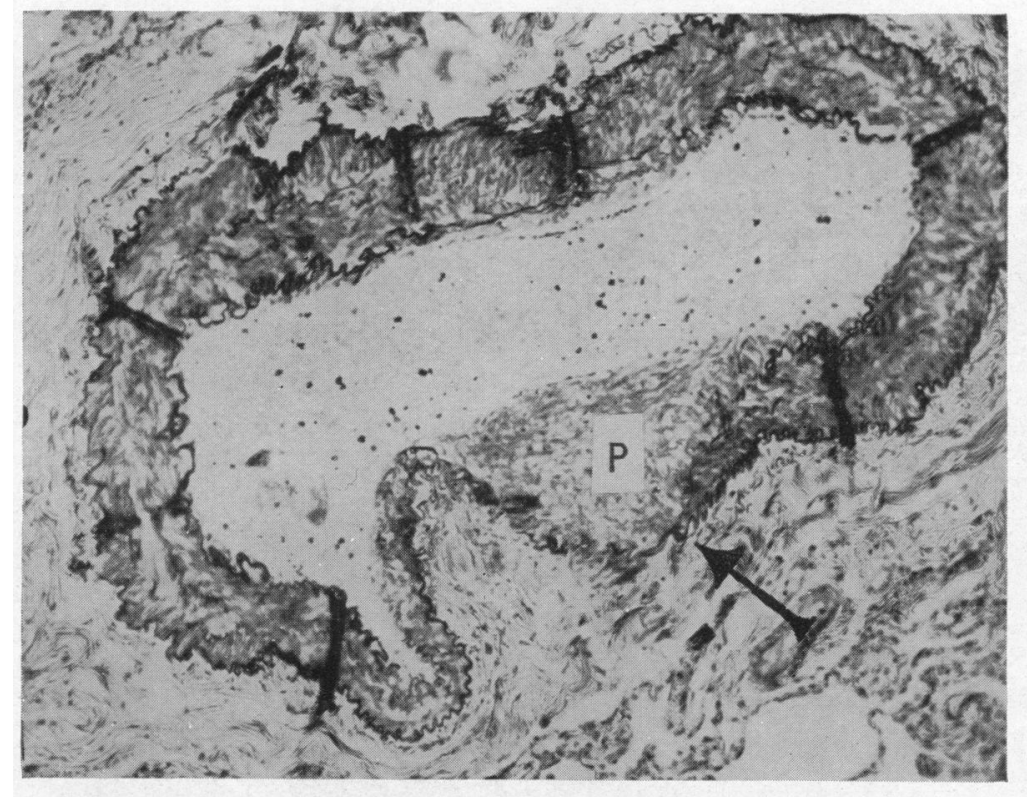

FIG. 16.-Muscular pulmonary artery $(\times 100)$ from Case 6. Intimal proliferation (P) formed in bay created by aplasia of the media where the internal and external elastic coats coalesce (arrow).

tion largely occluded the artery, the media was often hypoplastic or even aplastic around its entire circumference (Fig. 20). Occasionally in such circumstances the intimal tissue was seen to bulge through the defect in the arterial wall (Fig. 21). The intimal proliferation was often greatest at the mouths of arterial branches. Medial hypertrophy has often been described in pulmonary hypertension, but it is difficult to gauge owing to the varying degree of post-mortem contraction that may be present. We were unable to identify medial hypertrophy with assurance in most of our cases.

The arterioles usually showed intimal proliferation whenever the muscular arteries were obstructed (Fig. 22A and B), and once (Case 9) there was partial or complete arteriolar occlusion in the absence of any intimal proliferation in the muscular arteries (Fig. 22C). We failed to find in our cases a definite muscular coat between two elastic laminæ in vessels of arteriolar size as described in pulmonary hypertension 


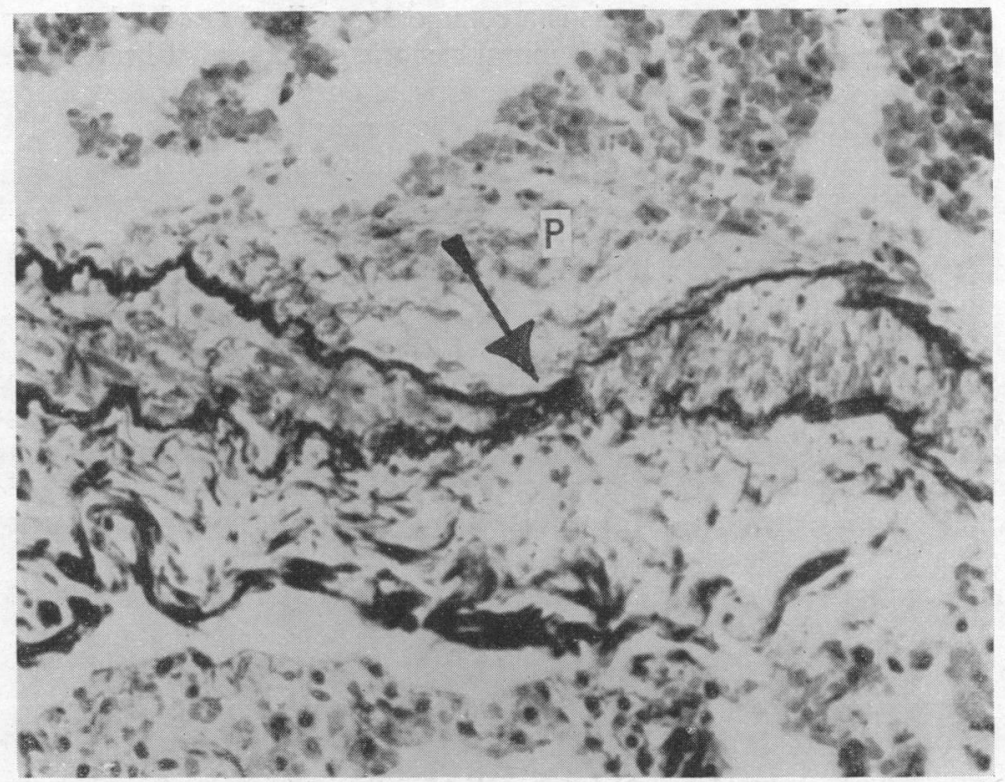

Fig. 17.-Section of muscular pulmonary artery $(\times 300)$ from Case 7. Intimal proliferation $(P)$ formed in the bay created by hypoplasia of media which has caused the internal and external elastic coats to become contiguous (arrow).

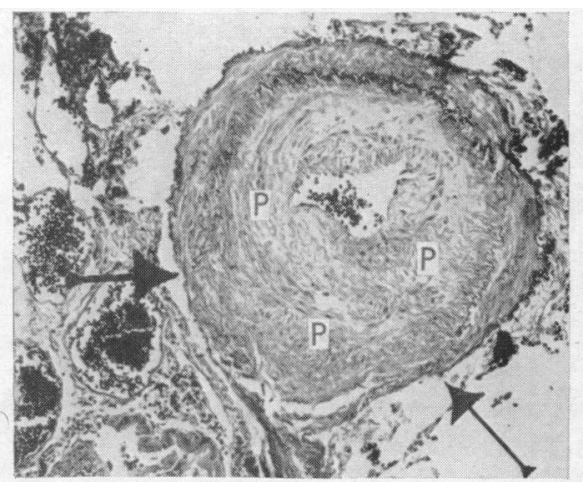

Fig. 18.-Muscular pulmonary artery $(\times 81)$ from Case 3. Intimal proliferation (PPP), producing great narrowing of lumen, has specially formed in bulge caused by aplasia of the media. The two elastic coats have coalesced at the edges of this bulge (arrow).

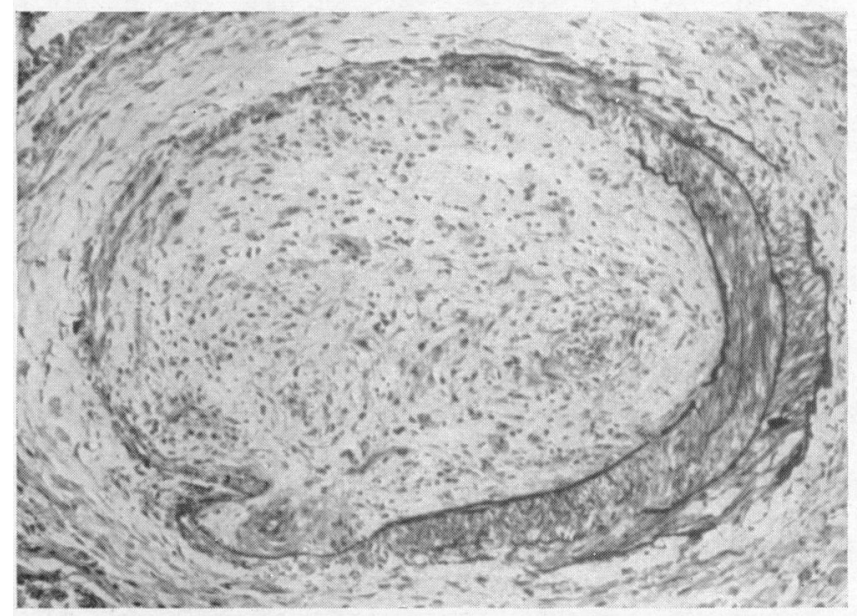

FIG. 19.-Large muscular pulmonary artery $(\times 81)$ from Case 2. Intimal proliferation has obliterated the lumen. Aplasia of the media with coalescence of the elastic coats involving half its circumference.

associated with mitral stenosis and with congenital heart disease by Henry (1952) and by Heath and Whitaker $(1955 a$ and $b)$.

In Cases 10 and 11 both the muscular arteries and the arterioles appeared normal on histological examination. An arteriogram was performed in one of these two, and showed diffuse narrowing of all the lobular arteries and arterioles to half the normal diameter (see Fig. 12B). The possibility that this appearance was 


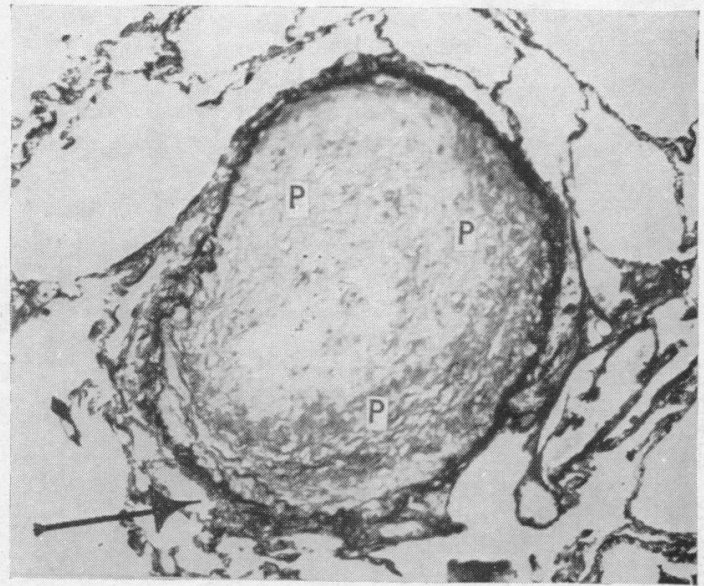

FIG. 20.-Large muscular pulmonary artery $(\times 79)$ from Case 4. Intimal proliferation (PPP) has almost closed the lumen. Aplasia of media has obliterated this coat over the whole circumference of the artery except for a small remnant (arrow).

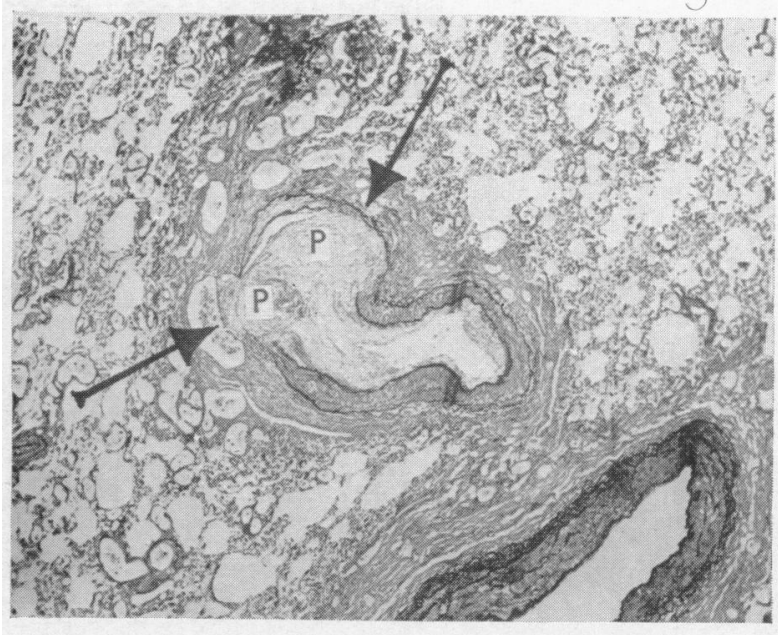

FIG. 21.-Large muscular pulmonary artery $(\times 26)$ from Case 4. Intimal proliferation (PP) has caused bulging (arrows) at places where external and internal elastic coats have coalesced from medial aplasia.
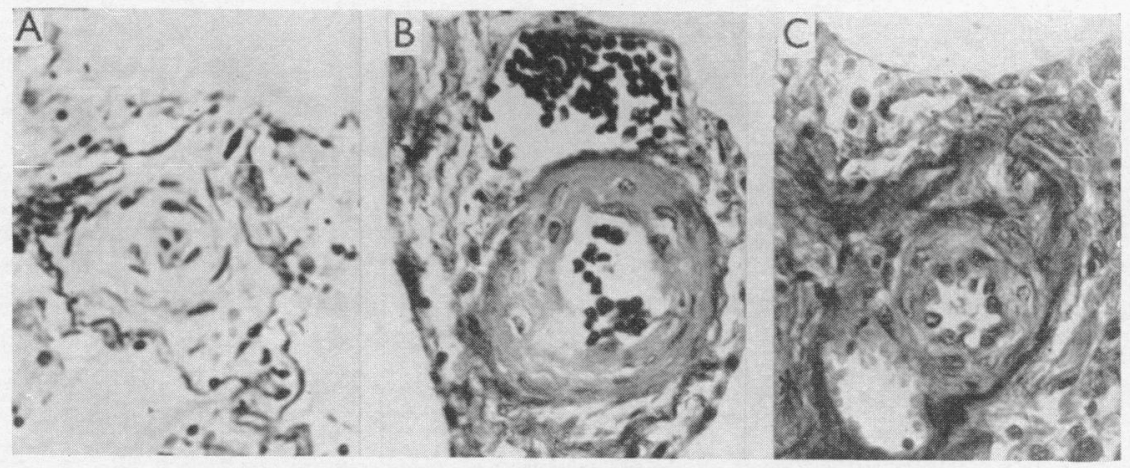

FIG. 22.-Pulmonary arteries $(\times 300)$, showing intimal proliferation, wholly (A) or partially (B) occluding lumen, from Cases 5 and 3 respectively. (C) Arteriolar obstruction, with pallisading appearance, from Case 9.

an artefact has been considered by Short (1956) and ruled out on the grounds that histological examination showed the entire arterial bed to have been fully distended and normally filled. It is concluded therefore that in this case (Case 11) and in Case 10 which resembled it histologically, pulmonary hypertension was due to a persistent reduction in calibre of the pulmonary vascular bed from lack of normal distensibility.

The venous system was generally normal, but two cases showed subintimal thickening in the venules which was more extensive than that appearing in our normal controls (Fig. 23). An identical appearance was noted by Mallory (1937) in a case of pulmonary vascular disease.

The extra-pulmonary bronchial arteries were normal, but their intrapulmonary branches were often prolific, especially in the neighbourhood of obliterated muscular or elastic arteries. In several cases, the presence of broncho-pulmonary anastomosis had been demonstrated.

\section{The Pathogenesis of Solitary Pulmonary Hypertension}

The main problem is to determine whether occlusive pulmonary vascular disease initiates hypertension, or whether hypertension based on some functional mechanism precedes and causes the 


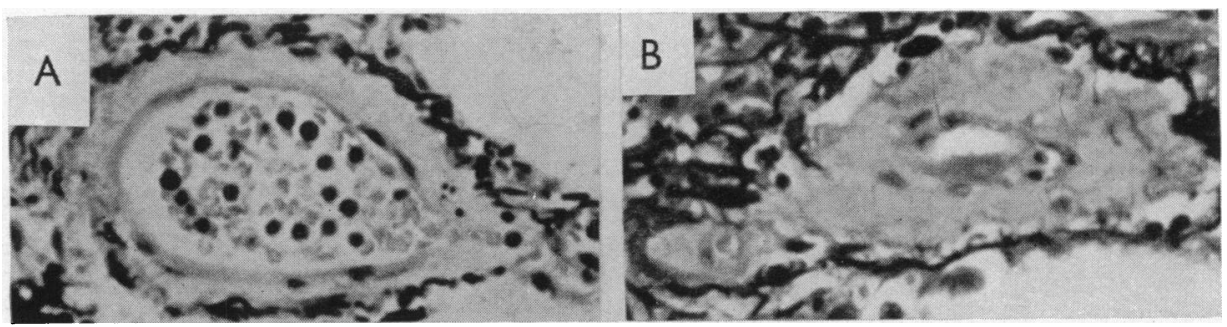

FIG. 23.-Pulmonary venules $(\times 300)$. Slight intimal thickening in (A) from a normal lung, but much greater in (B) from Case 11, where it almost closes the lumen.

arterial lesions. It is often stated that in some cases pulmonary arterial disease is absent or so slight that it is insufficient to explain hypertension. In 9 of our 11 cases the degree of vascular obstruction, especially when portrayed in an arteriogram of the whole pulmonary arterial tree, was ample to account for a maintenance of hypertension. In the remaining two no histological evidence of vascular disease was found, but an arteriogram performed in one of them showed a diffuse narrowing of the smaller arteries and arterioles to half their normal calibre, suggesting that there was an inability of the arterial tree to dilate, a sort of arterial achalasia. Such a condition would explain pulmonary hypertension under normal increases in pulmonary flow, and this in turn might initiate intimal proliferation. Edwards (1950) has invoked a similar mechanism to explain the pulmonary vascular disease of Eisenmenger's syndrome in which he believes there is a persistence of the narrow foetal pulmonary vasculature.

Bredt (1932), from a histological study of primary pulmonary arteriosclerosis, considered that the disease started in the media as a circumscribed loss of muscle and elastica, which was specially evident in arteries having a diameter of about $0.25 \mathrm{~mm}$.; the intima showed proliferation which was slight in the larger arteries but often occluded the smaller branches. Gilmour and Evans (1946) were the first to state that congenital deficiencies in the walls of the lesser pulmonary arteries supplied the cause of pulmonary hypertension of the solitary type. In one such case they found that foci of medial aplasia or hypoplasia in the small muscular arteries numbered many thousands, and that intimal proliferation over the deficiencies led to arterial stenosis or occlusion and to persistent hypertension. The present investigation has confirmed the frequency and importance of focal medial hypoplasia or aplasia in solitary pulmonary hypertension, supporting the view that these medial defects cause an intimal reaction to normal fluctuations in pulmonary arterial pressure, and in this way initiate hypertension.

Posselt (1908) reported three examples of primary pulmonary sclerosis in infants, in two of whom syphilis in the parents was considered to be the cause of the arterial lesions, and Ljungdahl in 1915 suggested that as the effects of pulmonary sclerosis had appeared in Posselt's cases in the first months of life, the condition might be a congenital abnormality. Clarke et al. (1927) cited the familial occurrence of pulmonary vascular disease as evidence of its congenital origin, and a similar example of familial incidence was reported by Dresdale et al. (1954). We sought other congenital abnormalities in our cases and found skeletal deformities in Case 2, congenital hypoplasia of the aorta and pulmonary trunk, abnormal origin of the vertebral artery and patent foramen ovale (pencil size) in Case 9, and patent foramen ovale (probe size) in Case 7.

In 1951 Evans, from a pathological investigation which included bronchial and pulmonary arteriography, considered the mechanism that in pulmonary hypertension of the primary kind depended on the presence of congenital medial deficiencies in the lesser pulmonary arteries, also operated in pulmonary hypertension whenever it was associated with congenital dilatation of the pulmonary artery, patent ductus arteriosus, atrial septal defect, pulmonary cystic disease, or emphysema. In that such a mechanism was common to these several clinical states, Evans considered that it justified their inclusion under the title of congenital pulmonary hypertension. 
The theory that intimal proliferation is of embolic or thrombotic origin is based partly on experimental evidence (Harrison, 1948; Barnard, 1954) and partly on authenticated cases of pulmonary hypertension associated with recurrent embolism (Castleman and Bland, 1946). Admitting that the histological distinction between intimal proliferation and organized thrombosis may be difficult, we still believe it is unlikely that embolism can explain many cases of isolated pulmonary hypertension, especially when it occurs in young subjects.

Brinton (1950) and Froment et al. (1954) have suggested that abnormal broncho-pulmonary anastomoses may cause pulmonary hypertension. There is indeed evidence that such a communication raises the pulmonary arterial pressure. Thus, Liebow et al. (1950) catheterized the pulmonary arteries in a patient with regional bronchiectasis, and found both the pressure and the oxygen saturation higher in the artery feeding the diseased part than in the branches supplying healthy portions of the lungs. In our cases, however, although abnormal broncho-pulmonary anastomoses were demonstrated, the extra-pulmonary bronchial arteries were not enlarged. It seems unlikely, therefore, that these vessels could carry sufficient blood to double the flow through the pulmonary arterioles, and even then the effect would be no greater than that of a moderate patent ductus arteriosus.

\section{SummaRY AND CONCLUSIONS}

Solitary pulmonary hypertension is defined as a persistent elevation of pulmonary arterial pressure sufficient to produce enlargement and ultimately failure of the right ventricle, where the cause is confined to obstruction in the lesser pulmonary arteries of intrinsic origin. We have described 11 cases, each investigated clinically and at necropsy.

The condition is far commoner in women than in men and all our cases happened to be female. Our youngest patient died at the age of 7 , the oldest at 64 ; the remaining nine survived to ages of between 20 and 40 years.

The dominant symptom was rapidly increasing dyspnœa on exertion which usually culminated in paroxysmal dyspnœa and orthopnœa. Cyanosis was absent or slight at the start but sometimes became intense later on when heart failure had set in. Finger clubbing was absent in all but one. Cardiac pain, always accompanied by dyspnœa, was present in 6 cases, and syncope in 5; both symptoms occurred either during effort or paroxysms of dyspnœa, and were attributed to a low cardiac output.

The pulse was small or became so, and the blood pressure a little low. The jugular venous pulse showed an exaggerated auricular wave in 6 cases. Palpation gave evidence of right ventricular hypertrophy as a rule. Auscultation at the pulmonary area usually showed an early systolic ejection sound, often a murmur maximal in mid-systole, a loud and closely split second sound, and in 4 cases a diastolic murmur of pulmonary incompetence. A triple rhythm at the apex was common late in the illness. Slight or moderate polycythæmia was found in 8 , sometimes with leucocytosis. The Wassermann reaction was always negative. Slight arterial anoxæmia was the rule.

Radiological findings included enlargement of the right atrium and ventricle, and dilatation of the pulmonary trunk. The main pulmonary branches were almost always enlarged, but the peripheral lung fields appeared ischæmic, and plethora was never seen. The electrocardiogram proved an indispensable test, always exhibiting the pattern of right ventricular hypertrophy especially in leads CR1 or V1, and usually with evidence of right atrial hypertrophy.

Cardiac catheterization, performed in 7 cases, excluded an intracardiac shunt and always showed considerable elevation of pulmonary arterial and right ventricular pressure.

The clinical course was inexorably downhill, the average duration of life from the onset of cardiac symptoms being $2 \frac{1}{2}$ years; this was less in the younger than in the older patients.

In diagnosis, chronic lung disease, mitral stenosis, and congenital heart disease had to be excluded. The distinction between solitary pulmonary hypertension and that resulting from recurrent pulmonary embolism sometimes proved impossible during life, and difficult even at necropsy. 
Pathological examination always showed hypertrophy of the right ventricle with dilatation of the pulmonary trunk and usually of its main branches. Thrombotic occlusion of one or more of the segmental branches was common. The pulmonary arteriogram portrayed the site and extent of arterial occlusion and the presence of abnormal arterial anastomoses, thus providing a valuable guide for histological examination.

The most significant histological changes were found in the muscular arteries and arterioles. These were partly or wholly occluded by intimal proliferation in which thrombosis with subsequent organization may have played a part. In the muscular arteries, the intimal changes were related to areas of hypoplasia or aplasia in the media. In nine cases, the vascular obstruction accounted for a maintenance of pulmonary hypertension. In the remaining two, no such obstruction was found on histological examination, but an arteriogram carried out in one of them showed a generalized constriction of the lesser pulmonary arteries, implying that a narrowed pulmonary vasculature (arterial achalasia) predisposed to the pulmonary hypertension.

Many colleagues have given invaluable aid in the clinical and pathological investigation of our 11 cases, which it is a pleasure to acknowledge. Thus, Cases 5, 8, and 11 were under the care of Dr. Frederic Jackson and Case 11 was referred to him by Dr. F. O. Graham, while Dr. B. E. Tomlinson examined them at necropsy. Case 2 was under the care of Dr. Paul Wood, Case 4 under Dr. W. Somerville, Case 9 under Dr. Wallace Brigden, Case 10 under Dr. J. H. L. Easton, and Case 7 under Dr. W. G. Wyllie. Dr. R. Hudson contributed to the pathological study of Cases 2 and 3 and gave valuable assistance throughout the investigation. Dr. M. Bodian helped with Case 7, and Dr. J. Valentine with Case 10. Professor Dorothy Russell and Dr. D. J. O'Brien gave us advice about Cases 1, 2, 5, 8, 9, and 11. Dr. J. Shillingford carried out the pulmonary arteriograms in the earlier cases. We wish to thank these several colleagues for help which each so readily gave us.

\section{REFERENCES}

Arrillaga, F. C. (1912). Esclerosis secundaria de la Arteria pulmonar y su Cuadro clinico (Cardiacos Negros). Buenos Aires.

Barnard, P. J. (1954). Circulation, 10, 343.

Berthrong, M., and Cochran, T. H. (1955). Johns Hopk. Hosp. Bull., 97, 69.

Bredt, H. (1932). Virch. Arch., 284, 136.

Brenner, O. (1935). Arch. intern. Med., 56, 211, 457, 724, 975, and 1189.

Brill, I. C., and Krygier, J. J. (1941). Arch. intern. Med., 68, 560.

Brinton, W. D. (1950). Brit. Heart J., 12, 305.

Castleman, B., and Bland, E. T. (1946). Arch. Path., 42, 581.

Clarke, R. C., Coombs, C. F., Hadfield, G., and Todd, A. T. (1927). Quart. J. Med., $21,51$.

Dexter, L. (1956). Brit. Heart J., 18, 209.

Dresdale, D. T., Michton, R. J., and Schultz, M. (1954). Bull. N.Y. Acad. Med., 30, 195.

, D. T., Schultz, M., and Michtom, R. J. (1951). Amer. J. Med., 11, 686.

Edwards, J. E. (1950). Proc. Inst. Med. Chicago, 18, 134.

Evans, W. (1951). Proc. Roy. Soc. Med., 44, 600.

Froment, R., Gaby, P., Tolot, F., Cohen, P., Gardere, J., and Ugnat, F. A. (1954). Rev. Lyon. Med., 3, 255.

Gilmour, J. R., and Evans, W. (1946). J. Path. Bact., 58, 687.

Goedel, A. (1930). Virch. Arch. path. Anat., 277, 507.

Harrison, C. V. (1948). J. Path. Bact., 60, 289.

Heath, D., and Whitaker, W. (1955). J. Path. Bact., 70, 285 and 291.

Henry, E. W. (1952). Brit. Heart J., 14, 406.

Howarth, S., and Lowe, J. B. (1953). Brit. Heart J., 15, 47.

Leatham, A., and Vogelpoel, L. (1954). Brit. Heart J., 16, 21.

Lenègre, J., and Gerbaux, A. (1952). Arch. Mal. Caur, 45, 289.

- (1955). Congrès Français de Médecine, 30th Session.

Lian, G. (1940). Arch. Mal. Caur, 33, 67.

Liebow, A. A., Hales, M. R., Harrison, W., Bloomer, W., and Lindskog, G. E. (1950). Yale J. Biol. Med., $22,637$.

Ljungdahl, M. (1915). Untersuchungen über die Arteriosklerose des kleinen Kreislaufs. J. F. Bergman, Wiesbaden.

Mallory, T. B. (1937). New Eng. J. Med., 217, 1045.

Moschcowitz, E. (1927). Amer. J. med. Sci., 174, 388.

Posselt, A. (1909). Ergeb. allg. Pathol. path. Anat., 13, 298.

Short, D. S. (1956). J. Fac. Radiol., to be published.

Steell, G. (1889). Med. Chron., 9, 182.

Stuckey, D. (1955). Brit. Heart J., 17, 397.

Vaquez, H., and Giroux, L. (1908). Bull. Mém. Soc. méd. Hôp. Paris, 26, 185.

Verloop, M. C. (1948). Acta Anat., 5, 171.

Viar, W. N., Harrison, T. R. (1952). Circulation, 5, 1.

Whitaker, W., Heath, D., and Brown, J. W. (1955). Brit. Heart J., 17, 121. 


\section{CASE Notes}

Glossary of Abbreviations. $\mathrm{MSL}=$ Midsternal line. $\mathrm{MCL}=$ Midclavicular line. $\mathrm{LA}=\mathrm{Left}$ atrium. $\quad L V=$ Left ventricle. $R A=$ Right atrium. $R V=$ Right ventricle. $S V C=$ Superior vena cava. $\mathrm{PA}=$ Pulmonary artery. RUL and $\mathrm{RLL}=$ Right upper and lower lobes. $\mathrm{LUL}$ and $\mathrm{LLL}=$ Left upper and lower lobes. $\mathrm{BP}=\mathrm{Blood}$ pressure in $\mathrm{mm}$. of $\mathrm{Hg}$. $\quad \mathrm{PCP}=$ Pulmonary capillary pressure. $\mathrm{RBC}=$ Red blood cells in millions per c.mm. WBC $=$ White blood cells per c.mm. $\mathrm{Hb}=$ Hæmoglobin expressed as percentage. $\mathrm{WR}=$ Wassermann reaction. Wt. $=$ Weight of heart. $\quad F O C=$ Foramen ovale closed. $\quad E C=$ Electrocardiogram.

Case 1. A. D., married woman, aged 36, seen in 1952, had been well until a breathless attack ten months before, after which she became breathless on slight exertion and had occasional hæmoptysis. Dyspnœa was soon joined by chest pain and tightness in the throat on effort, confining her to bed. Following attacks of nocturnal dyspnœa with constriction in the chest, she was admitted to hospital.

Examination. Cyanosed and orthopnœic; no finger clubbing. Pulse small and regular. BP 170/130 falling to an average level of 120/95. Large $a$ waves in jugular pulse. Apex beat in MCL, systolic lift over conus. Mitral systolic murmur and triple rhythm due to the third sound or opening snap; split second sound with very loud pulmonary element. Liver palpable, slight œdema of ankles, lungs clear. RBC 8·88, Hb 140, WBC 18,900 . WR negative.

Radiology. Moderate enlargement of RV and RA, pulmonary trunk and main branches. Peripheral lung fields ischæmic. Scar of infarct in RLL.

EC. Normal rhythm, RV hypertrophy.

Cardiac catheterization excluded an intracardiac shunt.

Course. She improved in hospital but after discharge was soon incapacitated by dyspnœa, chest pain on effort, recurrent hæmoptysis, and later she had repeated syncope while standing. Following attacks of nocturnal dyspnœa, she was readmitted to hospital in congestive failure with ascites. Pulse very small; BP 110/70. Auscultation showed a pulmonary diastolic murmur, a louder mitral systolic murmur, and the third heart sound or opening snap. Treatment was ineffective. Though the pulmonary hypertension was regarded as solitary, mitral stenosis could not be entirely excluded in view of the clinical signs, so that exploratory cardiotomy was performed and mitral disease excluded. PA pressure 70/40 mm. She became drowsy and died $2 \frac{1}{2}$ years after the onset of symptoms.

Necropsy. Very wasted cadaver. Customary signs of heart failure in viscera. No thrombosis of pelvic or femoral veins.

Heart. Wt. $330 \mathrm{~g}$. Dilatation and moderate hypertrophy of RV $(0.7 \mathrm{~cm}$. thick). Considerable dilatation of RA. Coronary arteries and valves normal. FOC. No congenital defects. Adherent thrombi in right auricular appendage and in RV.

Lungs. Massive thrombus, much of it old, in both pulmonary arteries, with complete occlusion of the main artery to the RLL. No emphysema.

Arteriogram (Fig. 9) showed no enlargement of PA or its primary branches, but there were a number of large filling defects due to occlusion of the pulmonary arteries as well as areas of opaque material indicating infarcts. Peripheral vessels where filled were natural. Normal bronchial artery filled with opaque medium.

Microscopy. Many elastic arteries occluded or greatly narrowed by organizing thrombus. Some muscular arteries healthy, others greatly obstructed by granulation tissue or intimal proliferation often associated with medial aplasia. Many arterioles similarly occluded and occasionally contrasted to show pallisading appearance. Bronchial arteries numerous.

Case 2. M. T., married woman, aged 24 , seen in 1952 , had a cardiac murmur at age of 18 months. When 15 , she fainted while running for a bus, and at this time was treated for rheumatism, after which she first noticed dyspnœa on exertion. When 23 , she was in hospital with pyrexia and pain in right iliac fossa; bacterial endocarditis was suspected and penicillin given; blood culture was negative. Thereafter, increasing breathlessness and fatigue on exertion set in. Some months later, attacks of nocturnal dyspnœa and a dry cough developed. Admitted to hospital with abdominal pain, nausea, and vomiting.

Examination. No cyanosis or clubbing of fingers. Pulse small and regular. BP 100/80. Large $a$ wave in jugular pulse. Apex beat $9 \mathrm{~cm}$. from MSL, of right ventricular type. Moderate systolic lift over RV. A sound in early systole, closely split second sound with loud pulmonary element, and early diastolic murmur heard in pulmonary area. No signs of heart failure. RBC 6.01, Hb 120, WBC 17,950. WR and Kahn negative. 
Radiology. Considerable enlargement of RV and RA. Pulmonary trunk and both main branches grossly dilated. Peripheral lung fields ischæmic.

EC. Normal rhythm, RV hypertrophy, large $\mathrm{P}$ waves.

Cardiac catheterization. PA mean pressure $63 \mathrm{~mm}$. $\mathrm{Hg}$. Oxygen saturation femoral artery, 93 per cent.

Course. In spite of rest and treatment, œdema of ankles spread to the trunk; pulse became impalpable, extremities cold, and dyspnœa increased. Right-sided pleurisy accompanied the onset of pulmonary infarction. After improving for a time, she became cyanosed, drowsy and breathless, the pulse rose to 150 , she complained of retrosternal discomfort, and died 6 weeks after admission and about 15 months from the onset of her main symptoms.

Necropsy. Customary signs of heart failure in viscera. No thrombosis of systemic veins.

Heart. Wt. $480 \mathrm{~g}$. Considerable enlargement of RV $(0.9 \mathrm{~cm}$. thick). LA and LV $(1.2 \mathrm{~cm}$. thick $)$ normal. RA slightly dilated. Coronary arteries and valves normal. FOC. No congenital defects or cardiac thrombosis.

Lungs. PA $8.8 \mathrm{~cm}$. circumference (aorta, $6.0 \mathrm{~cm}$.) and both branches greatly dilated, with minimal atheroma. Artery to RLL narrowed by thrombus near origin. Artery $(0.2 \mathrm{~cm}$. diam.) in RUL occluded by thrombus. No emphysema.

Microscopy. Elastic arteries showed only patchy intimal thickening. Muscular arteries showed hypoplasia and aplasia of media, their inner and outer coats coalescing (Fig. 19). Great intimal proliferation adjoining such deficiencies, partially or wholly occluding artery, and in places herniating through attenuated wall. Others showed focal necrosis with local bulging and overlying deposit of thrombus. Many vessels $(0.25 \mathrm{~mm}$. diam.) with normal intima, seemed thickened. Arterioles showed intimal proliferation. Bronchial arteries were natural.

Case 3. E. B. C., married woman, aged 62, was seen in March 1948. For 5 years she had been subject to constricting pain behind upper sternum, sometimes extending to both arms, on exertion and always associated with dyspnœa. In a severe attack of chest pain she had fainted and coronary thrombosis was suspected. Increasing dyspnœa on effort followed.

Examination. No cyanosis or clubbing of fingers. BP 140/85. Apex beat slightly displaced to left. No murmurs. Pulmonary second sound very loud and split. RBC 5.1, Hb 100, WR negative.

Radiology. Moderate enlargement of RA and RV; pulmonary trunk prominent, both main branches enlarged and pulsatile.

EC. Normal rhythm, RV hypertrophy, large $\mathbf{P}$ waves in lead II.

Cardiac catheterization. RV mean pressure $47 \mathrm{~mm}$. $\mathrm{Hg}$. Arterial oxygen saturation 84 per cent.

Course. She developed cough and hæmoptysis and was admitted to hospital in May 1949 in heart failure with cyanosis, cold extremities, and small pulse. Later she had four syncopal attacks, and died of heart failure 7 years after the onset of cardiac pain, and less than three years after her first symptoms of heart failure.

Necropsy. Customary signs of heart failure in viscera. No thrombosis of pelvic or femoral veins.

Heart. Great hypertrophy of RV $(1.3 \mathrm{~cm}$. thick). LV normal $(1 \cdot 1 \mathrm{~cm}$. thick). Coronary arteries and valves normal. FOC. No congenital defects or cardiac thrombosis.

Lungs. No infarction or emphysema. Considerable dilatation of PA $(2 \cdot 2 \mathrm{~cm}$. diam. compared with $1.8 \mathrm{~cm}$. for the aorta).

Microscopy. One or two elastic arteries occluded by thrombus. Hypoplasia and sometimes aplasia of many muscular arteries causing external and internal elastic layers to coalesce. Adjacent to these areas and elsewhere, conspicuous intimal proliferation caused severe narrowing or occlusion of the affected arteries (Fig. 18). Some arterioles appeared healthy, but many showed intimal proliferation which sometimes occluded these vessels (Fig. 22B). Many collateral vascular channels seen. Bronchial arteries prolific, especially near obstructed muscular arteries.

Case 4. P. M., a single woman, aged 21, seen in May 1955, had suffered from epilepsy since the age of 18 , but otherwise had remained well and free from symptoms until 10 months ago, when she had bronchitis and thereafter became breathless and cyanosed on exertion, so that she could only walk 25 yards without halting. For a month, cramp-like pain in left chest on effort was relieved by halting, and there were two short attacks of nocturnal dyspnœa with constriction in the throat and cough.

Examination. Pulse small and regular. BP 105/75. Jugular pulse showed giant $a$ waves. Apex beat of right ventricular type. Triple rhythm. Very loud split second sound in pulmonary area. No murmurs. 
Liver palpable. No œdema. A short walk provoked intense dyspnœa and cyanosis of lips and extremities. Hb 106, WBC 7,900. WR negative.

Radiology. RA prominent. Pulmonary trunk grossly dilated, main branches slightly enlarged, and peripheral lung fields ischæmic.

EC. Normal rhythm, RV hypertrophy, large P waves in leads II and III.

Cardiac catheterization. PA pressure $118 / 80 \mathrm{~mm}$. Hg. Arterial oxygen saturation: femoral artery, 70 per cent.

Course. Following a major epileptic fit, she became severely breathless and distressed, and died suddenly less than a year from the onset of symptoms.

Necropsy. Customary changes of heart failure in viscera. No thrombosis in pelvic or femoral veins.

Heart. Wt. $425 \mathrm{~g}$. Great hypertrophy of RV $(1.2 \mathrm{~cm}$. thick) (LV $0.9 \mathrm{~cm}$. thick). Hypertrophy and dilatation of RA. Coronary arteries and valves healthy. No congenital defects or cardiac thrombosis.

Lungs. Three small infarcts, but no evident thrombosis. Slight emphysema in LUL. PA dilated $(3.6 \mathrm{~cm}$. diam.) (aorta $2.0 \mathrm{~cm}$. diam.). Right arteriogram showed severe pruning of peripheral vascular pattern and moderate bronchial reflux (Fig. 11 and 13).

Microscopy. Non-occlusive thrombosis, of different ages, of large elastic arteries. Organizing thrombus often filling branches of muscular arteries at their origin. Many arteries partly or wholly filled with intimal proliferation showed medial hypoplasia or aplasia (Fig. 20 and 21). Many arterioles occluded, others merely ghosts. Undilated bronchial arteries prolific.

Case 5. N. V. R., a married woman, aged 24, was first seen in November 1951 when she was 5 months pregnant. Slight breathlessness for 2 years; worse since bronchitis a year ago. Dyspnœa had increased during pregnancy and a dry cough developed, but she had remained at work until admitted to hospital.

Examination. Pulse regular, 100. BP 105/75. Very loud pulmonary second sound. Triple rhythm at apex. Liver enlarged, œdema of ankles, and raised jugular venous pressure.

Radiology. Heart slightly enlarged with RA prominent. Pulmonary trunk and right main branch much enlarged, medium branches normal or narrowed, peripheral lung fields ischæmic.

EC. Normal rhythm, RV hypertrophy.

Course. Admitted to hospital for termination of pregnancy by hysterotomy. She died suddenly 4 days later and about 2 years after the onset of symptoms.

Necropsy. Customary signs of heart failure in viscera. No thrombosis of systemic veins.

Heart. Wt. $250 \mathrm{~g}$. Great dilatation of RV. Coronary arteries and valves normal. No congenital defects or cardiac thrombosis.

Lungs. No infarction or emphysema. Right pulmonary arteriogram showed great distension of right PA. Medium arteries appeared to be normal, but lesser ones were pruned.

Microscopy. Apart from a single elastic artery which was occluded by thrombus all vessels of a diameter greater than $0.2 \mathrm{~mm}$. were healthy. The small muscular arteries showed aplasia and hypoplasia of the media, and great intimal proliferation which often occluded the vessels. Similar intimal proliferation had closed many arterioles (Fig. 22A).

Case 6. M. A., a married Englishwoman, aged 33, with one child, was seen in November 1951. She had resided in India and E. Africa for several years, had been in good health until she became breathless when playing tennis, and thereafter noticed increasing dyspnœa accompanied by tightness in the chest on effort. Within 3 months, attacks of severe griping central chest pain apart from effort set in, followed by epigastric oppression, vomiting and abdominal distension, and by nocturnal dyspnœa, orthopnœa, and attacks of faintness on effort.

Examination. No cyanosis or clubbing of fingers. Pulse small and often impalpable. BP 95/70. Apex beat in MCL. No murmurs. Second sound in pulmonary area loud and split. Jugular veins distended and showing dominant $a$ waves. RBC 6.0, Hb 135, WBC 9,350. Arterial oxygen saturation 89 per cent. WR and Kahn negative. Urine and stools negative for bilharzia ova.

Radiology. Moderate enlargement of RA, RV, pulmonary trunk and main branches; peripheral lung fields ischæmic.

EC. Normal rhythm, RV hypertrophy.

Cardiac catheterization. PA pressure $67 / 25 \mathrm{~mm}$. Oxygen saturation: femoral artery 92 per cent. No evidence of intracardiac shunt.

Course. A diagnosis of solitary pulmonary hypertension was made. She improved on routine I 
treatment for heart failure, but on leaving hospital she deteriorated quickly and was readmitted. Examination then showed a pulmonary systolic click, a pulmonary diastolic murmur, triple rhythm, and signs of tricuspid incompetence. She developed increasing weakness, apathy, cyanosis with cold extremities, and finally repeated syncopal attacks without convulsions. She died $2 \frac{1}{2}$ years after the onset of symptoms.

Necropsy. Customary signs of heart failure in viscera. No thrombosis in pelvic or femoral veins.

Heart. Wt. $330 \mathrm{~g}$. Dilatation and hypertrophy of RA and RV $(1.0 \mathrm{~cm}$. thick as also was LV). Coronary arteries and valves healthy. FOC. No congenital defects or cardiac thrombosis.

Lungs. No infarction or emphysema. PA thin and slightly dilated, showing some atheroma. Thrombus in lesser arteries to RUL and RLL.

Microscopy. Prominent intimal proliferation in large elastic arteries. Similar intimal proliferation occasionally seen in large muscular arteries overlying areas of medial hypoplasia (Fig. 16). The main abnormalities found in vessels less than $0.15 \mathrm{~mm}$. diameter. Many of these showed medial aplasia with adjacent intimal proliferation causing severe narrowing and often complete occlusion. Similar occlusion in numerous arterioles. Collateral vascular channels evident. The bronchial arteries appeared normal.

Case 7. T. B., a girl, aged 7, admitted to hospital in March 1946, had been healthy and active until three months before when she became easily tired and breathless on effort.

Examination. Cyanosis. No clubbing of fingers. Pulse small, regular and 120. Orthopnœa. Apex beat $3.7 \mathrm{~cm}$. outside MCL. Mitral systolic murmur, splitting of second sound in the pulmonary area. Jugular veins distended and signs of tricuspid incompetence. Liver enlarged and œdema present.

Radiology. Great cardiac enlargement, mainly of RA and RV. Pulmonary trunk dilated, main branches normal, and peripheral lung fields ischæmic.

EC. Normal rhythm, RV hypertrophy, large $\mathbf{P}$ waves in lead II.

Course. Heart failure increased in spite of treatment. She collapsed and died suddenly 5 months after the onset of symptoms.

Necropsy. Customary signs of heart failure in viscera. No thrombosis in pelvic or femoral veins.

Heart. RV enlarged (RV $7 \mathrm{~mm}$. thick; LV $11 \mathrm{~mm}$. thick). Coronary arteries and valves normal. Foramen ovale patent to probe. Ductus arteriosus closed. Thrombus, size of walnut in RA.

Lungs. Thrombus blocking both main pulmonary arteries (Fig. 8). Two wedge-shaped infarcts in right lower lobe. No emphysema.

Microscopy. Elastic arteries showed widespread thrombosis often with recanalization. Similar changes or intimal proliferation in muscular arteries accompanying medial hypoplasia (Fig. 17) and also in arterioles, which were often occluded. Bronchial arteries prolific near thrombosed elastic arteries. Collateral vascular channels throughout lung.

Case 8. A. G., a married woman, aged 37, with two children had rheumatic fever at age of 21 , when her heart was suspected. Well until a year before, when she became breathless on effort; dyspnœea had increased in recent months when she became orthopnœic at night, and noticed upper chest pain after a busy day. Admitted to hospital in 1951.

Examination. Moderate cyanosis. Pulse small, regular, 136. BP 140/80. Jugular veins engorged. A moderate systolic murmur and loud second sound at pulmonary area. Liver enlarged. Slight odema of ankles and sacrum. Hb 120 . WBC 17,000 .

Radiology. RV and RA moderately enlarged. Pulmonary trunk prominent, main branches enlarged and peripheral lung fields of normal clarity.

$E C$. Normal rhythm, RV hypertrophy, large $\mathrm{P}$ waves.

Cardiac catheterization. PA mean pressure $74 \mathrm{~mm}$. Hg. PCP $4 \mathrm{~mm}$. Hg. Oxygen saturation: femoral artery, 89 per cent.

Course. Three weeks after leaving hospital she was readmitted on account of a sudden attack of leftsided chest pain and coughing with slight dyspnœa. Severe dyspnœa and deep cyanosis developed and she died half an hour later, one year after the onset of symptoms.

Necropsy. Customary signs of heart failure in viscera. No thrombosis of pelvic or femoral veins.

Heart. Wt. $400 \mathrm{~g}$. Hypertrophy of RV. Coronary arteries and valves normal. No congenital defects or cardiac thrombosis.

Lungs. Few atheromatous plaques in main PA branches. No infarction or emphysema. Left arteriogram showed enlargement of main branch with narrowing of the medium and the finest branches. 
Microscopy. Elastic arteries normal. Slight intimal proliferation within medium-sized muscular arteries. Greater proliferation, often containing conspicuous elastic tissue adjacent to areas of medial hypoplasia produced moderate narrowing of the smallest arteries. Some arterioles were partially obstructed by intimal proliferation. Moderate obstruction of venules by endothelial thickening. Bronchial arteries normal.

Case 9. V. R., a married woman, aged 27, was admitted to hospital in 1951 when three months pregnant. At age of 11, she was forbidden games on account of a heart murmur. When 16, syncopal attacks on exertion began and subsequently became more frequent. She had been slightly short-winded from the age of 16 , and at age of 26 dyspnoa became so severe that she could only walk 200 yards, and she had a choking sensation in the throat on effort which lasted half an hour. She also had several attacks of nocturnal dyspnœa with tightness in the throat, palpitation, and brief syncope.

Examination. No cyanosis or clubbing of fingers. Pulse 80, small and regular. BP 110/65. Apexbeat $10 \mathrm{~cm}$. from MSL and diffuse. Systolic lift over RV. Pulmonary diastolic thrill. Loud widespread systolic murmur, best heard at apex; pulmonary diastolic murmur obliterating the second sound. Liver palpable. No œdema. Lungs clear. Hb 95. WR negative.

Radiology. Gross enlargement of RV and RA; pulmonary trunk of aneurysmal size, main branches much enlarged, peripheral lung fields ischæmic. Small aorta.

EC. Normal rhythm, RV hypertrophy, normal $P$ waves.

Course. Pregnancy was allowed to continue and she left hospital, but was soon readmitted with attacks of nocturnal dyspnœa, palpitation, and constricting central chest pain extending to both arms. She died in 12 hours, following a syncopal attack with slight convulsions, one year after the onset of unequivocal cardiac symptoms.

Necropsy. Customary changes of heart failure in the viscera. No thrombosis of pelvic or femoral veins.

Heart. Wt. $524 \mathrm{~g}$. Dilatation of RA. Very great dilatation and hypertrophy of RV $(1.5 \mathrm{~cm}$. thick). Dilatation without obvious hypertrophy of LV $(1.0 \mathrm{~cm}$. thick). Coronary arteries and valves normal. Aorta was hypoplastic $(0.1 \mathrm{~cm}$. thick and $2.8 \mathrm{~cm}$. circumference). Valvular patency of foramen ovale $(1.3 \mathrm{~cm}$. diameter). Left vertebral artery arising from arch of aorta.

Lungs. No emphysema. Several small granulomatous foci. Great dilatation of PA forming fusiform swelling $(7.0 \mathrm{~cm}$. by $4.5 \mathrm{~cm}$.); both branches also greatly dilated. Fragment of organizing thrombus in artery to RUL, but without infarction here or elsewhere. Arteriogram showed dilatation of PA and its primary and secondary branches with pruning of terminal radicles.

Microscopy. Flecks of atheroma in elastic arteries. Muscular arteries appeared normal. Widespread obstruction of arterioles with pallisading appearance (Fig. 22C).

Case 10. J. B., a single woman, aged 31, seen in 1949, was healthy until two years before when she became breathless playing hockey, and noticed cyanosis of face and hands at times.

Examination. Slight cyanosis; curved nails. BP 110/70. Apex-beat $12 \mathrm{~cm}$. from MSL. Palpable pulmonary diastolic shock. Pulmonary systolic murmur and very loud second sound. Kahn negative. $\mathrm{Hb} 118$.

Radiology. Considerable enlargement of RA and RV, prominent pulmonary trunk and main branches. Peripheral lung fields normal.

EC. Normal rhythm, RV hypertrophy, large $\mathbf{P}$ waves in lead II.

Course. Symptoms hardly changed during next year, after which she developed a cough, became orthopnœic, and was admitted to hospital. Examination showed increased skin pigmentation, cyanosis and slight clubbing of fingers, orthopnœa, and râles over both lungs. A triple rhythm was audible. Venous pressure raised and liver enlarged. She died suddenly 3 years from the onset of symptoms.

Necropsy. Customary changes of heart failure in viscera with right pleural $(500 \mathrm{ml}$.$) and pericardial$ $(200 \mathrm{ml}$.) effusion. No thrombosis of systemic veins.

Heart. Greatly enlarged. Great hypertrophy of RV $(0.9 \mathrm{~cm}$.); slight dilatation and hypertrophy of RA. LA and LV $(1.4 \mathrm{~cm}$.) normal. Coronary arteries and valves normal. FOC. No congenital defects or thrombosis.

Lungs. No emphysema, thrombosis or infarction. Pulmonary artery trunk and main branches greatly dilated, with very slight atheroma.

Microscopy. Elastic arteries, muscular arteries and arterioles were patent and appeared normal in structure. Venules normal. Bronchial arteries more numerous than usual. 
Case 11. L. J., a married woman, aged 39, with two children, 1954, had experienced recurrent bronchitis for ten years. Dyspncea and orthopncea had been present for two years. She had been in another hospital with heart failure for several months.

Examination. Cyanosis. Pulse 80 regular. Giant $a$ waves in jugular pulse. BP 160/100 falling to 135/95. Right ventricular systolic lift. Very loud pulmonary second sound. Triple rhythm due to the third heart sound. Scattered rhonchi in chest. Hb 120. WBC 13,900.

Radiology. Considerable enlargement of RV and RA; pulmonary trunk and main branches much dilated with normal peripheral lung fields.

EC. Normal rhythm, RV hypertrophy, large $\mathrm{P}$ waves.

Cardiac catheterization. PA mean pressure exceeded $107 \mathrm{~mm}$. Hg. PCP $5 \mathrm{~mm}$. Hg. Oxygen saturation: femoral artery, 63 per cent rising to 95 per cent after breathing oxygen.

Course. She developed acute pulmonary œdema and died two years after initial significant symptoms.

Necropsy. Customary changes of heart failure in viscera. No thrombosis of pelvic or femoral veins.

Heart. Wt. $400 \mathrm{~g}$. Great dilatation and hypertrophy of RA and RV $(1.0 \mathrm{~cm}$. thick). Coronary arteries and valves normal. No congenital defects or cardiac thrombosis.

Lungs. Small bullæ, on surface, but no substantial emphysema. No pulmonary infarction. Scattered small foci of sarcoidosis, mostly in lymph glands, but a few in lungs. PA dilated and showing patchy atheroma. Arteriogram (Fig. 12) showed generalized narrowing of finest vessels.

Microscopy. Elastic arteries, muscular arteries and arterioles appeared normal in structure. Venules frequently showed endothelial thickening which caused considerable reduction in size of lumen (Fig. 23B). Bronchial arteries prolific. 